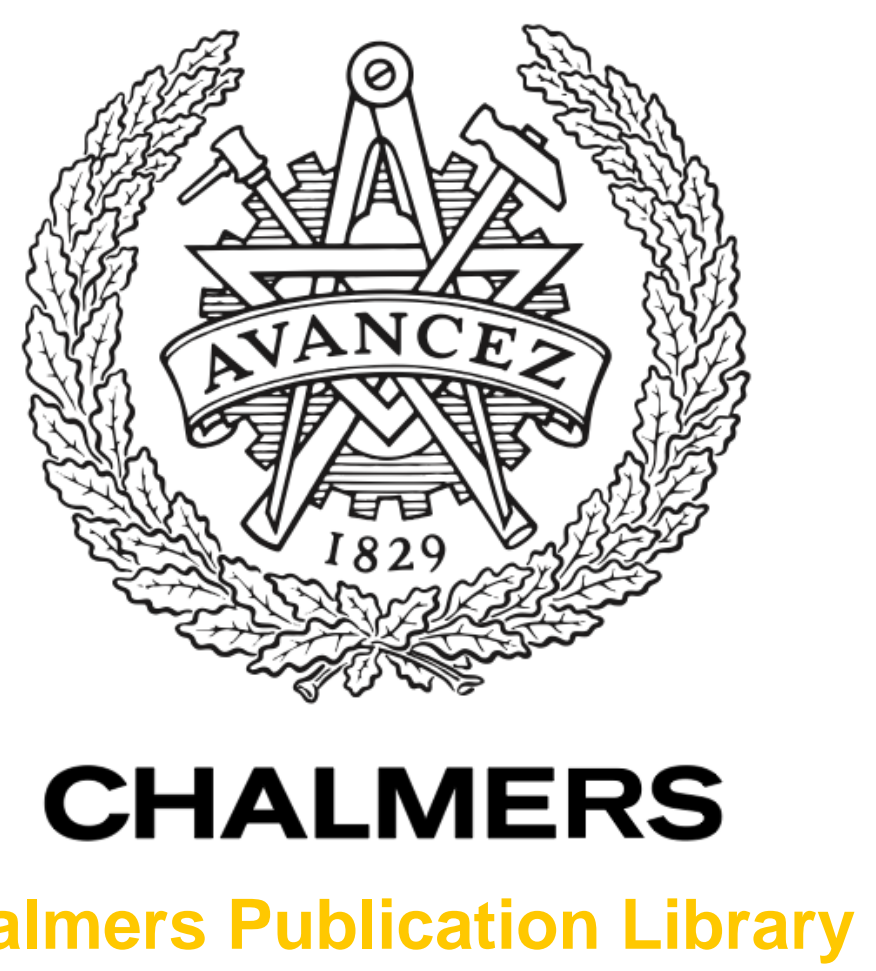

\title{
Regression-Based Retrieval of Boreal Forest Biomass in Sloping Terrain using P- band SAR Backscatter Intensity Data
}

This document has been downloaded from Chalmers Publication Library (CPL). It is the author's version of a work that was accepted for publication in:

IEEE Transactions on Geoscience and Remote Sensing (ISSN: 0196-2892)

Citation for the published paper:

Soja, M. ; Sandberg, G. ; Ulander, L. (2013) "Regression-Based Retrieval of Boreal Forest Biomass in Sloping Terrain using P-band SAR Backscatter Intensity Data". IEEE

Transactions on Geoscience and Remote Sensing, vol. 51(5), pp. 2646-2665.

http://dx.doi.org/10.1109/TGRS.2012.2219538

Downloaded from: http://publications.lib.chalmers.se/publication/176903

Notice: Changes introduced as a result of publishing processes such as copy-editing and formatting may not be reflected in this document. For a definitive version of this work, please refer to the published source. Please note that access to the published version might require a subscription. 


\title{
Regression-Based Retrieval of Boreal Forest Biomass in Sloping Terrain using P-band SAR Backscatter Intensity Data
}

\author{
Maciej Jerzy Soja, Gustaf Sandberg, and Lars M. H. Ulander, Senior Member, IEEE
}

\begin{abstract}
A new biomass retrieval model for boreal forest using polarimetric P-band SAR backscatter is presented. The model is based on two main SAR quantities: the HV backscatter and the HH/VV backscatter ratio. It also includes a topographic correction based on the ground slope. The model is developed from analysis of stand-wise data from two airborne P-band SAR campaigns: BioSAR 2007 (test site: Remningstorp, southern Sweden, biomass range: $10-287$ tons/ha, slope range: $0-4^{\circ}$ ) and BioSAR 2008 (test site: Krycklan, northern Sweden, biomass range: $8-257$ tons/ha, slope range: $0-19^{\circ}$ ). The new model is compared to five other models in a set of tests to evaluate its performance in different conditions.

All models are first tested on data sets from Remningstorp with different moisture conditions, acquired during three periods in the spring of 2007. Thereafter, the models are tested in topographic terrain using SAR data acquired for different flight headings in Krycklan. The models are also evaluated across sites, i.e. training on one site followed by validation on the other site. Using the new model with parameters estimated on Krycklan data, biomass in Remningstorp is retrieved with RMSE of 4059 tons/ha, or $22-32 \%$ of the mean biomass, which is lower compared to the other models. In the inverse scenario, the examined site is not well represented in the training data set and the results are therefore not conclusive.
\end{abstract}

Index Terms-Biomass retrieval, boreal forest, P-band, synthetic aperture radar (SAR), topographic correction

\section{INTRODUCTION}

$\mathbf{F}$ ACING the threat of global warming one of the most important topics in climate research is understanding the terrestrial carbon cycle and predicting future climate changes. One of the major uncertainties in the current carbon cycle models lies in terrestrial ecosystems, in particular forests [1]. Moreover, up to $20 \%$ of the global emissions of carbon dioxide are estimated to come from deforestation [2]. Accurate, global-scale forest mapping is therefore one of the most important elements of climate modelling. Current global forest maps are simply too inaccurate for this task, creating a demand for the development of new tools.

The most relevant quantity directly related to the forestal carbon stock is aboveground dry biomass (further on simply

M. J. Soja, G. Sandberg and L. M. H. Ulander are with the Department of Earth and Space Sciences, Chalmers University of Technology, 41296 Gothenburg, Sweden.

L. M. H. Ulander is also with the Radar Systems Unit, Swedish Defence Research Agency, 58111 Linköping, Sweden.

For correspondence, please contact M. J. Soja at maciej.soja@chalmers.se

Manuscript received N/A; revised N/A. This work was supported by the Swedish National Space Board (SNSB) and the European Space Agency (ESA). called "biomass"). Biomass is the dry weight of aboveground forest, including stem, bark, branches, and needles/leaves, but excluding stump and roots. Biomass is usually measured in metric tons per hectare $\left(1 \mathrm{ton} / \mathrm{ha}=0.1 \mathrm{~kg} / \mathrm{m}^{2}\right)$.

Currently, the most accurate technique for remote biomass mapping is small-footprint lidar scanning (see [3] and references therein). However, accurate lidar-based biomass estimation requires high-quality plot-level measurements for training. Biomass tends also to be underestimated as small trees may be covered by large trees blocking the laser beam. As with all optical methods, measurement accuracy is dependent on weather conditions. In reality, small-footprint lidar scanning is inefficient for global biomass mapping. Spaceborne lidar has been considered a possible alternative, but complications arise chiefly due to large footprint and low coverage, and there are currently no ongoing spaceborne lidar missions.

Synthetic Aperture Radar (SAR) is a high-resolution, microwave imaging sensor which is weather-independent and provides its own illumination. Moreover, SAR systems can be customised to fit a particular task through the choice of system parameters (frequency, polarisation, incidence angle, and imaging mode).

SAR imaging at low frequencies (here: below L-band) has proven itself especially useful for biomass mapping due to its superior penetration capabilities and sensitivity to a wide range of biomass levels. Due to transmission restrictions, there neither are, nor have been, any satellites in Earth's orbit with a SAR sensor operating below L-band. Therefore, all lowfrequency studies have been performed using data acquired with airborne platforms. The low VHF-band $(20-90 \mathrm{MHz})$ SAR system CARABAS-II, run by the Swedish Defence Research Agency (FOI), has previously proven itself useful for accurate stem volume estimation (see [4] and references therein).

Also, several P-band (approximately $0.20-0.45 \mathrm{GHz}$ ) studies have been performed using data acquired with airborne SAR systems [5]-[17]. In all these studies, regression models relating biomass to SAR observables are derived (see Table I for a summary of these models). They all conclude that biomass and radar backscatter are correlated, but the presented functions and their regions of validity differ (due to different biomes and moisture conditions, different acquisition platforms, and changes in forest structure and surface topography). This means that the models derived in these papers usually have little or no application outside the studied test site. This is an obvious disadvantage when global biomass mapping is 
TABLE I

SUMMARY OF SOME PREVIOUS STUDIES IN WHICH BIOMASS OR STEM VOLUME WERE RELATED TO P-BAND BACKSCATTER THROUGH REGRESSION. MODELS INCLUDING BACKSCATTER AT OTHER FREQUENCIES THAN P-BAND WERE DISREGARDED. IN SOME CASES, MODELS WERE JUST HINTED (FOR EXAMPLE THROUGH A STUDY OF CORRELATION), BUT NOT EXPLICITLY DEFINED OR USED IN THE TEXT [5], [7]. NOTE, THAT IN THE CASES OF [10], [12], AND [13] FORWARD MODELS ARE DEFINED.

\begin{tabular}{|c|c|c|c|c|c|}
\hline Ref.: & $\begin{array}{l}\text { Sensor (cam- } \\
\text { paign): }\end{array}$ & Test site: & Forest type: & Model structure: & Modelled quantity: \\
\hline$[5]$ & $\begin{array}{l}\text { AirSAR } \\
\text { (MAESTRO 1) }\end{array}$ & Landes (southern France) & maritime pine & $\begin{array}{l}\text { hinted: linear function of } \mathrm{HV} \text { in linear } \\
\text { units }\end{array}$ & trunk biomass \\
\hline$[6]$ & $\begin{array}{l}\text { AirSAR } \\
\text { (MAESTRO 1) }\end{array}$ & $\begin{array}{l}\text { Landes and Duke Univer- } \\
\text { sity Forest, (North Car- } \\
\text { olina, USA) }\end{array}$ & $\begin{array}{l}\text { maritime pine and lolloby } \\
\text { pine, respectively }\end{array}$ & linear function of $\mathrm{HV}$ in linear units & aboveground biomass \\
\hline$[7]$ & $\begin{array}{l}\text { AirSAR } \\
(\text { MAESTRO 1) }\end{array}$ & $\begin{array}{l}\text { Flevoland } \quad \text { (the } \\
\text { Netherlands) }\end{array}$ & $\begin{array}{l}\text { poplar and ash studied } \\
\text { here, also other deciduous } \\
\text { and coniferous in test site }\end{array}$ & $\begin{array}{l}\text { hinted: linear functions of single polar- } \\
\text { isation }(\mathrm{HH}, \mathrm{VV}, \mathrm{HV} \text {, all in } \mathrm{dB})\end{array}$ & $\begin{array}{l}\text { logarithm of stem vol- } \\
\text { ume }\end{array}$ \\
\hline$[8]$ & $\begin{array}{l}\text { AirSAR } \\
(\text { MAESTRO 1) }\end{array}$ & $\begin{array}{l}\text { Freiburg (south-west Ger- } \\
\text { many) }\end{array}$ & $\begin{array}{l}\text { Norway spruce, } \\
\text { pine, silver fir, } \\
\text { deciduous }\end{array}$ & linear function of $\mathrm{HV}$ in $\mathrm{dB}$ & stem volume \\
\hline [9] & AirSAR & Howland (Maine, USA) & $\begin{array}{l}\text { boreal coniferous and } \\
\text { northern hardwood }\end{array}$ & linear function of $\mathrm{HV}$ in $\mathrm{dB}$ & $\begin{array}{l}\text { logarithm of above- } \\
\text { ground biomass }\end{array}$ \\
\hline$[10]$ & AirSAR & 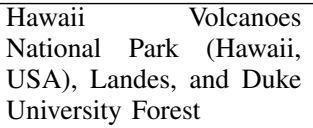 & $\begin{array}{l}\text { broadleaf evergreen, mar- } \\
\text { itime pine, and lolloby } \\
\text { pine, respectively }\end{array}$ & $\begin{array}{l}\text { third order polynomials of above- } \\
\text { ground biomass (evergreen and com- } \\
\text { bined) or logarithm of aboveground } \\
\text { biomass (pine) }\end{array}$ & $\begin{array}{l}\text { backscatter in dB } \\
(\mathrm{HH}, \mathrm{VV}, \mathrm{HV})\end{array}$ \\
\hline [11] & AirSAR & $\begin{array}{l}\text { Landes, Duke University } \\
\text { Forest, Bonanza Creek ex- } \\
\text { perimental forest (Alaska, } \\
\text { USA), and Manu National } \\
\text { Park (Peru) }\end{array}$ & $\begin{array}{l}\text { maritime pine, lolloby } \\
\text { pine, boreal forest, and } \\
\text { primary tropical rain } \\
\text { forest, respectively }\end{array}$ & $\begin{array}{l}\text { linear function of multiple polarisations } \\
(\mathrm{HH}, \mathrm{VV}, \mathrm{HV} \text {, all in } \mathrm{dB}) \text {, and their } \\
\text { ratios and squares }\end{array}$ & $\begin{array}{l}\text { logarithm of above- } \\
\text { ground biomass }\end{array}$ \\
\hline$[12]$ & AirSAR & $\begin{array}{l}\text { Guaviere } \quad \text { (Colombian } \\
\text { Amazon) }\end{array}$ & $\begin{array}{l}\text { primary and secondary } \\
\text { forest, recently cut forest, } \\
\text { pastures }\end{array}$ & $\begin{array}{l}\text { power function of aboveground } \\
\text { biomass }\end{array}$ & $\begin{array}{l}\text { backscatter in dB } \\
(\mathrm{HH}, \mathrm{VV}, \mathrm{HV})\end{array}$ \\
\hline$[13]$ & SAR AeS & $\begin{array}{l}\text { Tapajós River region (Pará } \\
\text { State, Brazil) }\end{array}$ & $\begin{array}{l}\text { primary rainforest and } \\
\text { secondary succession }\end{array}$ & $\begin{array}{l}\text { linear functions of logarithm of above- } \\
\text { ground biomass and third order polyno- } \\
\text { mials of aboveground biomass }\end{array}$ & $\begin{array}{l}\text { backscatter in dB } \\
(\mathrm{HH}, \mathrm{VV}, \mathrm{HV})\end{array}$ \\
\hline$[14]$ & AirSAR & $\begin{array}{l}\text { Yellowstone National Park } \\
\text { (USA) }\end{array}$ & $\begin{array}{l}\text { coniferous (mainly lodge- } \\
\text { pole pine) }\end{array}$ & $\begin{array}{l}\text { linear function of multiple polarisa- } \\
\text { tions ( } \mathrm{HH}, \mathrm{VV}, \mathrm{HV} \text {, all in } \mathrm{dB}) \text {, and } \\
\text { their squared terms, all including topo- } \\
\text { graphic corrections }\end{array}$ & $\begin{array}{l}\text { logarithm of above- } \\
\text { ground biomass (sep- } \\
\text { arately for trunk and } \\
\text { crown) }\end{array}$ \\
\hline$[15]$ & $\begin{array}{l}\text { ESAR } \\
\text { (BioSAR } \\
2007)\end{array}$ & $\begin{array}{l}\text { Remningstorp } \quad \text { (southern } \\
\text { Sweden) }\end{array}$ & $\begin{array}{l}\text { boreal (Norway spruce, } \\
\text { Scots pine, birch) }\end{array}$ & $\begin{array}{l}\text { linear functions of multiple polarisa- } \\
\text { tions normalised to gamma nought } \\
(\mathrm{HH}, \mathrm{HV} \text {, both in } \mathrm{dB})\end{array}$ & $\begin{array}{l}\text { square root of above- } \\
\text { ground biomass }\end{array}$ \\
\hline$[16]$ & AirSAR & La Selva (Costa Rica) & $\begin{array}{l}\text { lowland old growth and } \\
\text { secondary tropical wet } \\
\text { forest }\end{array}$ & $\begin{array}{l}\text { linear functions of multiple polarisa- } \\
\text { tions ( } \mathrm{HH}, \mathrm{VV}, \mathrm{HV} \text {, all in } \mathrm{dB}) \text { and } \\
\text { InSAR height }\end{array}$ & $\begin{array}{l}\text { square root of above- } \\
\text { ground biomass }\end{array}$ \\
\hline$[17]$ & $\begin{array}{l}\text { ESAR } \\
(\text { BioSAR } \\
2008)\end{array}$ & $\begin{array}{l}\text { Krycklan (northern Swe- } \\
\text { den) }\end{array}$ & $\begin{array}{l}\text { boreal coniferous (mostly } \\
\text { Norway spruce and Scots } \\
\text { pine) }\end{array}$ & $\begin{array}{l}\text { linear functions of multiple polarisa- } \\
\text { tions ( } \mathrm{HH}, \mathrm{VV}, \mathrm{HV} \text {, all in } \mathrm{dB}) \text {, InSAR } \\
\text { height, and several PolInSAR indicators }\end{array}$ & aboveground biomass \\
\hline
\end{tabular}

concerned.

At low frequencies, radio waves are generally scattered from larger objects, which in the case of trees means trunks and large branches. The increased temporal stability (as compared to for example X-band) makes it possible to perform repeatpass polarimetric SAR interferometry (PolInSAR), which produces forest height estimates [18]-[20]. However, both PolInSAR-based height estimation and allometric height-tobiomass conversion are sensitive to parameters such as vertical structure, species composition, and management procedures [21]. Since it is not likely that these parameters can be estimated accurately with radar, accurate biomass estimation from PolInSAR is aggravated. Possible improvements include multi-baseline PolInSAR [22], [23] and different tomographic techniques [24]-[26]. However, these techniques require the acquisition of high-quality multi-baseline data, which is a very costly and time consuming process.

Although the temporal stability and biomass sensitivity are both improved at low frequencies, a different problem occurs instead: ground topography. The double-bounce effect (scattering between ground and trunk, or vice versa) is very prominent at low frequencies and ground tilt has an obvious influence. This issue has been addressed in [27], where a physical-optics model was successfully used to describe the influence of topography on radar backscatter from forests (at both VHF- and P-band). In [4], [28], a simplified approach based on electromagnetic models like those described in [29][34] was used at VHF-band to reduce topography influence, giving stem volume retrieval results comparable to those for flat ground. In this text, an even simpler approach will be used. The influence of topography will be examined as the change in model parameters for some reference models and the most prominent factors will be included.

Due to the recent opening of the P-band at frequencies $432-438 \mathrm{MHz}$ for spaceborne use (World Radiocommunications Conference 2003 [35]), a fully polarimetric P-band SAR satellite system called BIOMASS has been proposed to European Space Agency (ESA) for the 7th Earth Explorer 


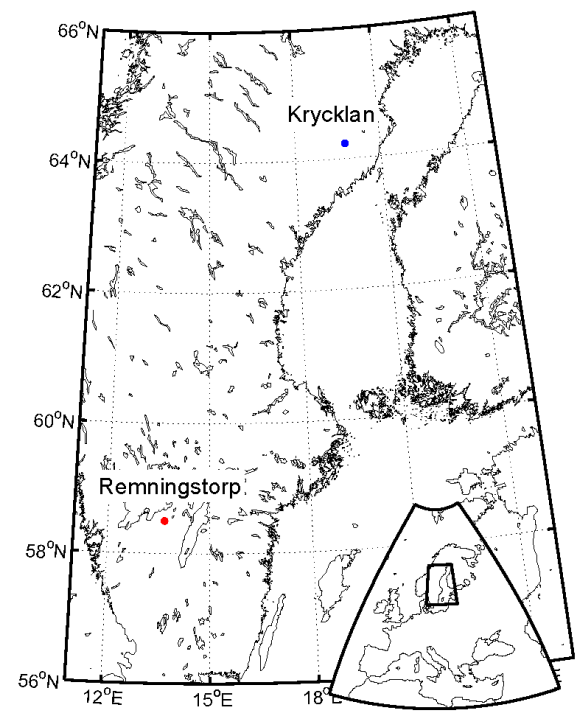

Fig. 1. The two test sites used in BioSAR 2007 and BioSAR 2008 campaigns are shown here. The test area in Remningstorp was covered by SAR imagery in the spring of 2007, whereas Krycklan was covered in October 2008. The distance between the two sites is $720 \mathrm{~km}$.

mission [35]-[39]. The system is planned to employ both intensity-based biomass retrieval and PolInSAR-based height retrieval. The two methods show different performance in different environments and are complementary, thus extending the capability of the proposed satellite.

In this paper, a new model for biomass retrieval from polarimetric SAR backscatter is presented. The model is tested for its sensitivity to site topography and for temporal change. Also, the model is compared to some previously published models, and evaluated using two sets of test data. The data were acquired within two BioSAR campaigns performed in 2007 and 2008 in the two test sites Remningstorp and Krycklan, respectively, both situated in Sweden. The test sites are located $720 \mathrm{~km}$ apart, and represent two different cases of boreal forest. In previous papers dealing with biomass retrieval from BioSAR data, the two test sites were treated separately [15], [17], [40]-[42]. In this paper, models fitted to data from one test site are evaluated on the other. In this manner, the model is validated independently of the training data set. An excerpt of the results presented here has been published in [43].

This paper begins with a brief description of the experimental data (Sec. II). Next, in Sec. III, the previously published models are presented and the new model is introduced. Thereafter, the models are evaluated with respect to temporal change, topographic change, and across-site retrieval (Sec. IV). The results are summarised and conclusions are drawn in Sec. V.

\section{EXPERIMENTAL DATA}

The experimental data used in this paper were acquired within two BioSAR campaigns conducted by the airborne Ex-

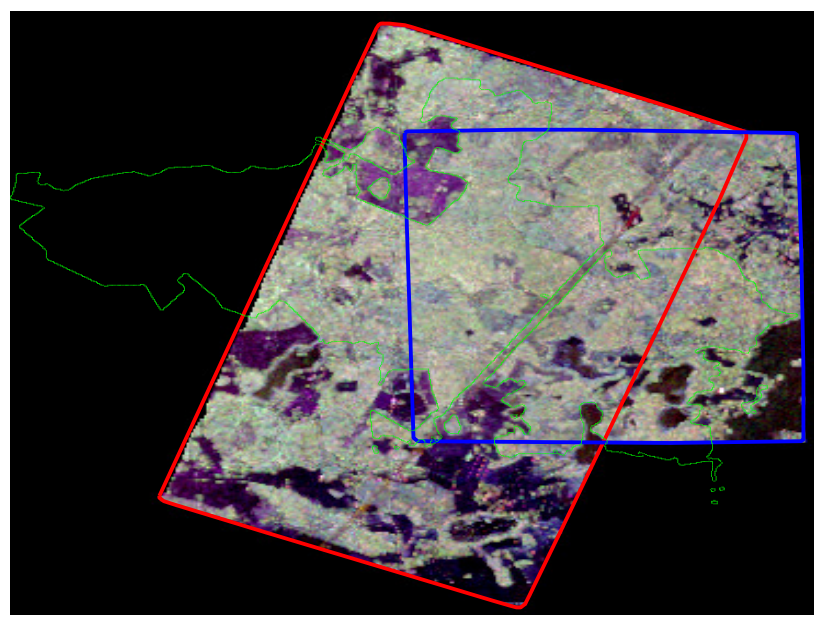

(a) BioSAR 2007: Remningstorp

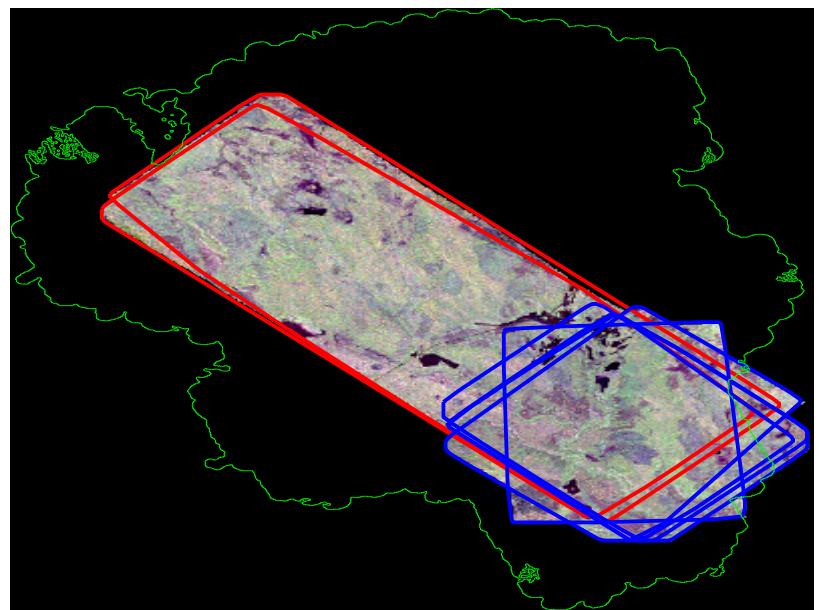

(b) BioSAR 2008: Krycklan

Fig. 2. Different acquisitions headings are visualised here. In red, image frames for the main headings are shown (headings used for PolInSAR height retrieval and SAR tomography, $200^{\circ}$ in Remningstorp, $134^{\circ}$ and $314^{\circ}$ in Krycklan). In blue, image frames for additional headings are shown $\left(179^{\circ}\right.$ in Remningstorp, $43^{\circ}, 134^{\circ}$ (flown twice), $314^{\circ}$, and $358^{\circ}$ in Krycklan). In green, the borders of the test sites are shown. As background, polarimetric SAR images are used ( $\mathrm{HH}$ in the red channel, HV in the green channel, and $\mathrm{VV}$ in the blue channel; all channels are scaled for optimal viewing). ESAR is a left-looking system.

perimental SAR (ESAR) platform from the German Aerospace Center (DLR). Ground-truth data were collected and processed by Swedish University of Agricultural Sciences (SLU).

\section{A. Test Sites}

BioSAR 2007 was conducted in Remningstorp (58 $28^{\prime} \mathrm{N}$, $13^{\circ} 38^{\prime}$ E) situated in southern Sweden, see Fig. 1. Remningstorp is fairly flat with ground slopes at stand level less than $5^{\circ}$ (computed from a $50 \mathrm{~m} \times 50 \mathrm{~m}$ digital elevation model, DEM). The test site covers approximately 1200 ha of productive forest land, and the forest consists primarily of Norway spruce (Picea abies (L.) Karst.), Scots pine (Pinus sylvestris L.), and birch (Betula spp.). For a thorough description of the campaign, see [15], [44].

BioSAR 2008 was conducted in Krycklan $\left(64^{\circ} 14^{\prime} \mathrm{N}\right.$, $19^{\circ} 46^{\prime}$ E) located in northern Sweden, see Fig. 1. Krycklan 
TABLE II

SUMMARY OF AVAILABLE BIOMASS REFERENCE DATA. ONLY STANDS COMPLETELY COVERED BY P-BAND SAR DATA ARE INCLUDED. SID STANDS FOR "Site ID" (RE FOR REMNINGSTORP, KR FOR KRYCKLAN). GID STANDS FOR "GROUP ID" AND REFERS TO TYPE OF STAND-WISE DATA SET (BASED ON

MAIN DATA SOURCE). N IS THE SIZE OF EACH DATA SET. TYPE REFERS TO THE CORRECT DENOMINATION OF THE DATA POINTS, AS IT WOULD BE

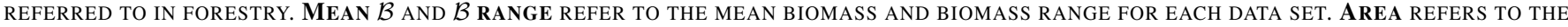
STAND AREa (OR AREA RANGE) IN HECTARES. ERror REFERS to THE ESTIMATED STANDARD BIOMASS ERROR (IF IN \%, THEN RELATIVE MEAN $\mathcal{B}$, IF A PERCENTAGE INTERVAL, THEN DIFFERENT PERCENTAGE FOR EACH STAND RELATIVE ITS MEAN BIOMASS)

\begin{tabular}{|l|l|l|l|l|l|l|l|l|}
\hline SID: & GID: & N: & Type: & Main data source: & Mean $\mathcal{B}$ & $\mathcal{B}$ range: & Area range: & Error: \\
\hline \multirow{2}{*}{$\operatorname{Re}$} & $I N S$ & 10 & plots & plot-level measurements & 181 & $52-267$ & $0.66-0.69$ & a few percent \\
\cline { 2 - 10 } & $L I D$ & 58 & stands & stem volume map, species stratification info & 129 & $10-287$ & $0.50-9.4$ & 25 tons/ha \\
\hline \multirow{2}{*}{$\mathrm{Kr}$} & $I N S$ & 29 & stands & plot-level measurements & 95 & $23-183$ & $1.5-22$ & $4-21 \%$ \\
\cline { 2 - 10 } & $L I D$ & 97 & plots & biomass map & 76 & $8-257$ & 0.79 & $16 \%$ \\
\hline
\end{tabular}

is situated $720 \mathrm{~km}$ north-north-east of Remningstorp. Unlike Remningstorp, Krycklan has a strongly undulating topography with ground slopes on stand level up to $19^{\circ}$ (again, computed from a $50 \mathrm{~m} \times 50 \mathrm{~m} \mathrm{DEM})$. The forest is dominated by Norway spruce and Scots pine. For a thorough description of the campaign, see [45].

It is worth mentioning that a third BioSAR campaign has been conducted in Remningstorp in October 2010, aiming at the detection of long-term temporal changes in Remningstorp, see [46], [47]. However, data processing and analysis were not finished at the time of writing of this text and this campaign is thus not included.

In the following text, the two test sites will sometimes be referred to as Re (Remningstorp) and Kr (Krycklan).

\section{B. In-situ and Laser Scanning Data}

In conjunction with both BioSAR campaigns, plot-level in-situ data and airborne lidar scanning data were collected for the estimation of biomass. Species stratification information extracted from aerial photography was also used to aid biomass estimation. Biomass maps with $10 \mathrm{~m} \times 10 \mathrm{~m}$ pixels were produced for both Remningstorp and Krycklan. Slightly different data collection strategies and estimation procedures were used for the two campaigns, and campaign reports should be consulted for a thorough description [44], [45].

Table II summarises four reference data sets used in this work, together with their approximate error levels and their type. In forestry, a distinction between "plots" and "stands" is made. Stands are relatively homogenous forest regions with similar species composition, biophysical characteristics (e.g. height and tree number density), and management procedures. They can vary in size and shape, and they are the main unit used for forest mapping and management [48]. Plots are usually smaller stand subsets of regular shape, which are used as within-stand samples. They are usually distributed in a regular pattern. For each test site, two data sets are available. Here follows a short description of these data sets.

The first data set in Remningstorp consists of 10 $80 \mathrm{~m} \times 80 \mathrm{~m}$ plots [44]. Only trees with stem diameter at breast height (dbh, measured $1.3 \mathrm{~m}$ above ground level) larger than $5 \mathrm{~cm}$ were included in the measurements. Position, dbh, and species were measured for all relevant trees for all 10 plots. Tree height was measured for all trees in 4 plots, and for a subset of trees in the other 6 plots. Biomass was then estimated for each single tree using Marklund's species specific allometric formulas, see [49]. The biomass estimation error (standard deviation of the residuals) computed using error estimates found in [49] is estimated to a few percent [15]

The second data set in Remningstorp consists of 58 stands of irregular shape and sizes between 0.5 and 9.4 hectares [44]. A systematic grid of 849 circular field plots (radius $10 \mathrm{~m}$ ) with a spacing of approximately $40 \mathrm{~m}$ was used. Within each field plot, all trees with dbh larger than $5 \mathrm{~cm}$ were calipered, and tree height was measured for approximately $10 \%$ of these trees. These data were then used together with lidar scanning data and species stratification information to obtain estimates of biomass for all 58 stands. The estimated standard biomass error for these 58 stands is 25 tons/ha, computed using validation against the 10 plots described in the previous paragraph, see [15]

The first data set in Krycklan consists of 29 stands of irregular shape and sizes between 1.5 and 22 hectares [45]. Systematic grids of circular field plots (radius $10 \mathrm{~m}$ ) were laid out in each stand. The spacing of each grid was selected to give approximately 10 field plots per stand. For each field plot, all trees with dbh larger than $4 \mathrm{~cm}$ were calipered and the species was determined. Tree height and age were also measured for approximately 1.5 randomly chosen sample trees in each field plot. Biomass was then determined using Petersson's biomass functions [50]. The estimated standard biomass error was computed based on the number of field plots within each stand and the variation between these plots within each stand [45], [51]. This error estimate varies between 4 and 21 percent, depending on stand.

The second data set in Krycklan consists of 97 plots. This set has been introduced in [41] and it is based on data acquired from airborne lidar scanning. Functions estimating biomass from lidar observables were derived using multiple regression and studies of residuals based on field plot data (both from the previously mentioned field plots situated within stands and additional 110 field plots randomly positioned in the central part of the Krycklan test site). A biomass map was then created using lidar data with additional species information acquired from aerial stereo photography interpretation. 97 circular plots (radius $50 \mathrm{~m}$ ) were selected within the region fully covered by the biomass map and SAR images for all four flight headings (see Sec. II-C and Fig. 2(b)), and mean biomass estimates were extracted from the biomass map. The plots were selected to have as constant ground slope as possible. The standard biomass error was here estimated to be $16 \%$, which is equal to the error of the corresponding biomass map, for which it was computed by cross-validation against the previously mentioned 
29 stands [45].

As it can be observed, biomass estimates for the data sets based on plot-level measurements are generally more accurate than for those based on maps and lidar data. In this text, the available reference data will therefore be divided in two groups. The stands and plots with biomass estimated only from plot-level in-situ measurements will be referred to as $I N S$-stands, while the other data sets will be referred to as $L I D$-stands, see Table II. Note, that although the stands can vary drastically in size $(0.5-22 \mathrm{ha})$, the number of looks is at least 390 (for the 0.5-hectare stands, see [15]), which allows to disregard the variation in stand area in the further analysis.

\section{SAR Data}

In Remningstorp, P-band SAR data were collected during three different periods of spring 2007: 3rd of March, 31st March to 2nd of April, and 2nd of May. At each occasion, two flight headings were used for P-band: $179^{\circ}$ and $200^{\circ}$ relative north, marked in blue and red, respectively, in Fig. 2(a). The first track features steeper incidence angles for all stands, close to those expected for a spaceborne scenario (all stands lie in near range with nominal incidence angles between $26^{\circ}$ and $35^{\circ}$ ). The second track features a wider range of incidence angles (between $30^{\circ}$ and $50^{\circ}$ ). It was flown several times at each occasion at different baselines in order to provide PolInSAR and tomographic data. No precipitation was observed within 24 hours prior to the acquisitions in the vicinity of the observation point $\left(58^{\circ} 27^{\prime} \mathrm{N}, 13^{\circ} 40^{\prime} \mathrm{E}\right.$, one automatic weather station maintained by the Swedish Meteorological and Hydrological Institute, SMHI). Field notes and photography from March show, that the forest soil was often saturated by water and standing water on the surface was commonly observed, most often due to the recently melted snow present in these areas. In April and May, corresponding observations show, that the ground had dried out and the soil moisture was considerably lower. These observations are consistent with the fact, that May and June are generally the driest period of the year in the region.

In Krycklan, P-band SAR data were acquired during two days only: 14th and 15th of October 2008. The first day, the main flight track $\left(134^{\circ}\right)$ was flown several times at different baselines for PolInSAR use. The same area was also covered from the opposite direction $\left(314^{\circ}\right)$. The second day, SAR data of a smaller area were collected from four directions (headings: $43^{\circ}, 134^{\circ}, 314^{\circ}$, and $358^{\circ}$ relative north). These additional flight tracks were selected in such a way, that the regions with strongest topographic variability were covered by data from all flight tracks. In Fig. 2(b), an overview for the different acquisitions is shown. Image frames for the two main acquisitions are shown in red, whereas image frames for the additional acquisitions are shown in blue. No precipitation was observed at the test site before and during the acquisitions. Weather conditions were recorded using an operational weather station found at the nearby Svarteberget Research Station and soil moisture was measured using samples from 10 stands in Krycklan. For a thorough description of the weather and soil moisture data, see [45].

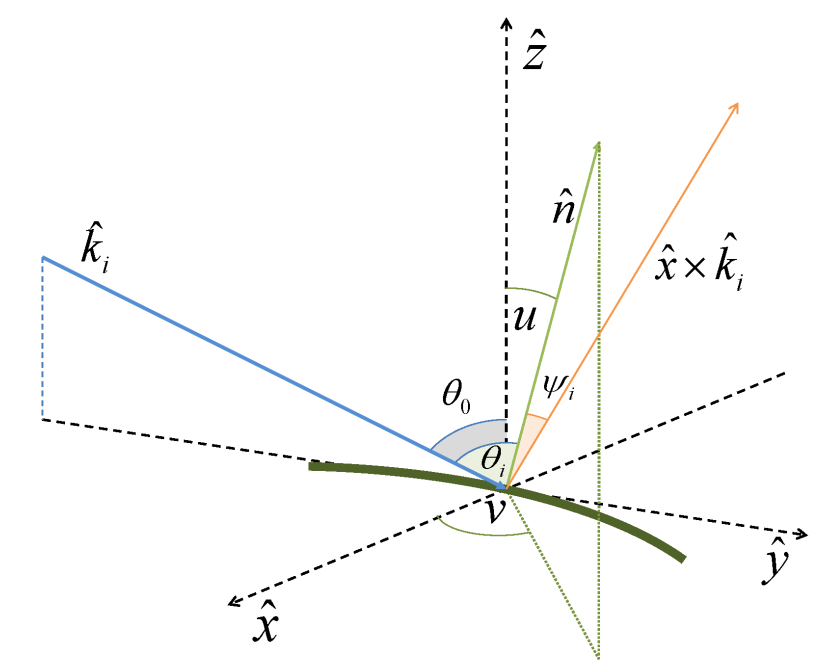

Fig. 3. Basic acquisition geometry. The ground normal is $\widehat{n}$ and the ground slope is defined by the two angles $u$ and $v$. The incident unit wavevector $\widehat{k}_{i}$ is assumed to lie in the $y$-z-plane.

Averaged, stand-wise backscatter data were extracted from the geocoded SAR images for each stand in both Remningstorp and Krycklan. A $50 \mathrm{~m} \times 50 \mathrm{~m}$ DEM was used for geocoding and normalisation. Although high-resolution lidar DEMs were also available for both test sites, they were not used because the evaluation scenario would be less realistic as comparable DEM resolutions are not available on global scale. All normalisation procedures were performed before averaging, that is on high-resolution SAR data. A buffer zone of $10 \mathrm{~m}$ was also added to avoid border effects. In some cases, there were several geocoded SAR images acquired in the same scenario (same site, same imaging geometry, and same acquisition occasion). Also, not all stands were covered by all images, and thus the number of available stands was different for different scenarios. In Table III, the number of stands and the number of geocoded SAR images available for each scenario are shown.

Henceforth, the different data sets will in some cases be referred to using shorter notation:

- Site ID (SID): Re for Remningstorp and Kr for Krycklan,

- Group ID (GID): INS for in-situ based stand-wise data, and $L I D$ for lidar based stand-wise data,

- Date ID (DID): $M a r, A p r$, and May for the acquisitions in Remningstorp in 2007, and Oct for the acquisitions in Krycklan in 2008.

\section{Biomass Retrieval Models}

In the following section, the models evaluated in this paper will be described. A motivation for the selection of the models introduced in this paper will be given. The basic geometry is shown in Fig. 3.

In this paper, the following convention will be used:

$$
[X]_{\mathrm{dB}}=10 \log _{10}(X),
$$

where $X$ is a power ratio. Also,

$$
\widehat{\mathcal{W}}_{\mathrm{Mn}}=\log _{10}\left(\widehat{\mathcal{B}}_{\mathrm{Mn}}\right) \text {, }
$$


TABLE III

SUMmary OF AVAILABlE STAND-WISE SAR DATA. SID STANDS FOR "SiTE ID" (RE FOR REMNINGSTORP, KR FOR KRYCKLAN). DID STANDS FOR "DATE ID" AND REFERS TO THE ACQUISITION DATE. IMAGE ID REFERS TO THE IMAGE IDENTIFICATION NUMBERS AS DEFINED IN [44], [45]. GID STANDS FOR "GROUP ID" AND REFERS TO TYPE OF STAND-WISE DATA SET ( $L I D$ FOR LIDAR MEASUREMENT-BASED STANDS, AND INS FOR in-Situ MEASUREMENT-BASED STANDS). COVERED STANDS REFERS TO THE NUMBER OF STANDS COVERED FOR EACH SCENE, RESPECTIVELY. BIOMASS RANGE REFERS TO THE BIOMASS RANGE OF THE COVERED STANDS (IN TONS/HA) FOR EACH SCENE, RESPECTIVELY. CONSULT ALSO TABLE II FOR A DESCRIPTION OF THE DIFFERENT REFERENCE DATA SETS.

\begin{tabular}{|c|c|c|c|c|c|c|}
\hline SID: & DID: & Heading: & Image ID: & GID: & Covered stands: & Biomass range: \\
\hline \multirow{12}{*}{$\mathrm{Re}$} & \multirow{4}{*}{ Mar } & \multirow{2}{*}{$179^{\circ}$} & \multirow{2}{*}{$\underline{0110}$} & $I N S$ & 9 & $52-267$ \\
\hline & & & & $L I D$ & 46 & $10-287$ \\
\hline & & \multirow{2}{*}{$200^{\circ}$} & \multirow{2}{*}{$\underline{0105}, \underline{0109}$} & $I N S$ & 10,10 & $52-267,52-267$ \\
\hline & & & & $L I D$ & 58,58 & $10-287,10-287$ \\
\hline & \multirow{4}{*}{$A p r$} & \multirow{2}{*}{$179^{\circ}$} & \multirow{2}{*}{$\underline{0206}$} & $I N S$ & 9 & $52-267$ \\
\hline & & & & $L I D$ & 46 & $10-287$ \\
\hline & & \multirow{2}{*}{$200^{\circ}$} & \multirow{2}{*}{$\underline{0301}, \underline{0306}$} & $I N S$ & 10,10 & $52-267,52-267$ \\
\hline & & & & $L I D$ & 58,58 & $10-287,10-287$ \\
\hline & \multirow{4}{*}{ May } & \multirow{2}{*}{$179^{\circ}$} & \multirow{2}{*}{$\underline{0412}$} & $I N S$ & 9 & $52-267$ \\
\hline & & & & $L I D$ & 46 & $10-287$ \\
\hline & & \multirow{2}{*}{$200^{\circ}$} & \multirow{2}{*}{$\underline{0406}, \underline{0411}$} & $I N S$ & 10,10 & $52-267,52-267$ \\
\hline & & & & $L I D$ & 58,58 & $10-287,10-287$ \\
\hline \multirow{8}{*}{$\mathrm{Kr}$} & \multirow{8}{*}{ Oct } & \multirow{2}{*}{$43^{\circ}$} & \multirow{2}{*}{0304} & $I N S$ & 10 & $27-167$ \\
\hline & & & & $L I D$ & 97 & $8-257$ \\
\hline & & \multirow{2}{*}{$134^{\circ}$} & \multirow{2}{*}{$\underline{0104}, \underline{0303}, \underline{0305}$} & $I N S$ & $28,9,10$ & $23-183,27-167,27-167$ \\
\hline & & & & $L I D$ & $97,97,97$ & $8-257,8-257,8-257$ \\
\hline & & \multirow{2}{*}{$314^{\circ}$} & \multirow{2}{*}{$\underline{0103}, \underline{0302}$} & $I N S$ & 27,10 & $27-183,27-167$ \\
\hline & & & & $L I D$ & 97,97 & $8-257,8-257$ \\
\hline & & \multirow{2}{*}{$358^{\circ}$} & \multirow{2}{*}{$\underline{0301}$} & $I N S$ & 9 & $27-167$ \\
\hline & & & & $L I D$ & 97 & $8-257$ \\
\hline
\end{tabular}

where $\widehat{\mathcal{B}}_{\mathrm{Mn}}$ is a biomass estimate from model $\mathrm{Mn}$ in tons/ha.

The scattering coefficient $\sigma^{0}$ is the averaged radar cross section (RCS) per unit area [52]. It can be defined as:

$$
\sigma_{\mathrm{PQ}}^{0}=\frac{4 \pi\left\langle\left|S_{\mathrm{PQ}}\right|^{2}\right\rangle}{A},
$$

where $S_{\mathrm{PQ}}$ is the scattering matrix element for polarisation PQ and $A$ is the area of a resolution cell. It is common to choose $A$ to be the projection of a slant range resolution cell to the ground [53]:

$$
A=\frac{A_{0}}{\cos \psi_{i}}
$$

where $A_{0}$ is the area of the slant range resolution cell, and $\cos \psi_{i}$ is a projection factor:

$$
\cos \psi_{i}=\hat{n} \cdot\left(\hat{x} \times \hat{k}_{i}\right),
$$

where $\hat{n}$ is the ground surface normal unit vector, $\hat{x}$ is the unit vector pointing in the flight direction, and $\hat{k}_{i}$ is the unit vector pointing in the propagation direction, see Fig. 3.

For a rough, forested surface, the normalisation to $\sigma^{0}$ is not sufficient due to a residual dependence on the angle of incidence (caused by different penetration depths). A better normalisation called $\gamma^{0}$ is used:

$$
\gamma_{\mathrm{PQ}}^{0}=\frac{\sigma_{\mathrm{PQ}}^{0}}{\cos \theta_{i}},
$$

where $\theta_{i}$ is the local incidence angle, see Fig. 3 .

\section{A. Topographic and Temporal Effects}

In Fig. 4, scattering coefficients for $\mathrm{HH}, \mathrm{HV}$, and VV, and the ratio $\mathrm{HH} / \mathrm{VV}$ are plotted against biomass for all data from Remningstorp and Krycklan. The $x$-axes are the same for all four plots. The $y$-axes have the same scale (spacing between grid lines), but the values are shifted for better viewing. Colour coding refers to the acquisition time. Running average curves are also plotted in order to simplify trend investigation.

Looking at the three polarisations $\mathrm{HH}, \mathrm{HV}$, and $\mathrm{VV}$ in Fig. 4, the following observations can be made:

1) VV backscatter is poorly correlated with biomass in all cases,

2) HH backscatter shows much higher variability in Krycklan than in Remningstorp,

3) backscatter at all polarisations is typically several $\mathrm{dB}$ lower in Krycklan than in Remningstorp,

4) reduced sensitivity can be observed in Krycklan at all polarisations above approximately 100 tons/ha,

5) an average backscatter shift by around $0-2 \mathrm{~dB}$ can be seen from March to May in the Remningstorp data.

Following point 1) it can be concluded that, of all polarisations, VV is least sensitive to biomass, making it a potential indicator of other properties, such as topography, moisture conditions, and forest structure. The observation from point 2) can be explained with the influence of topography. Krycklan data feature higher slopes and better directional representation for each stand (acquisitions from multiple headings). The backscatter shift referred to in 3) may be explained by different forest structure and moisture change. Also, the problem described in 4) is most certainly an effect of topography (most of the high-biomass $L I D$-stands in Krycklan are located in topographic terrain, see Fig. 6 and Sec. III-C). Finally, the backscatter shift in 5) is most likely due to moisture change. Radiometric calibration has been carefully evaluated using trihedral corner reflectors (see [44]) and the maximal measured variation is only $0.8 \mathrm{~dB}$. It is thus concluded that the measured backscatter shift cannot be explained by a radiometric calibration error. 


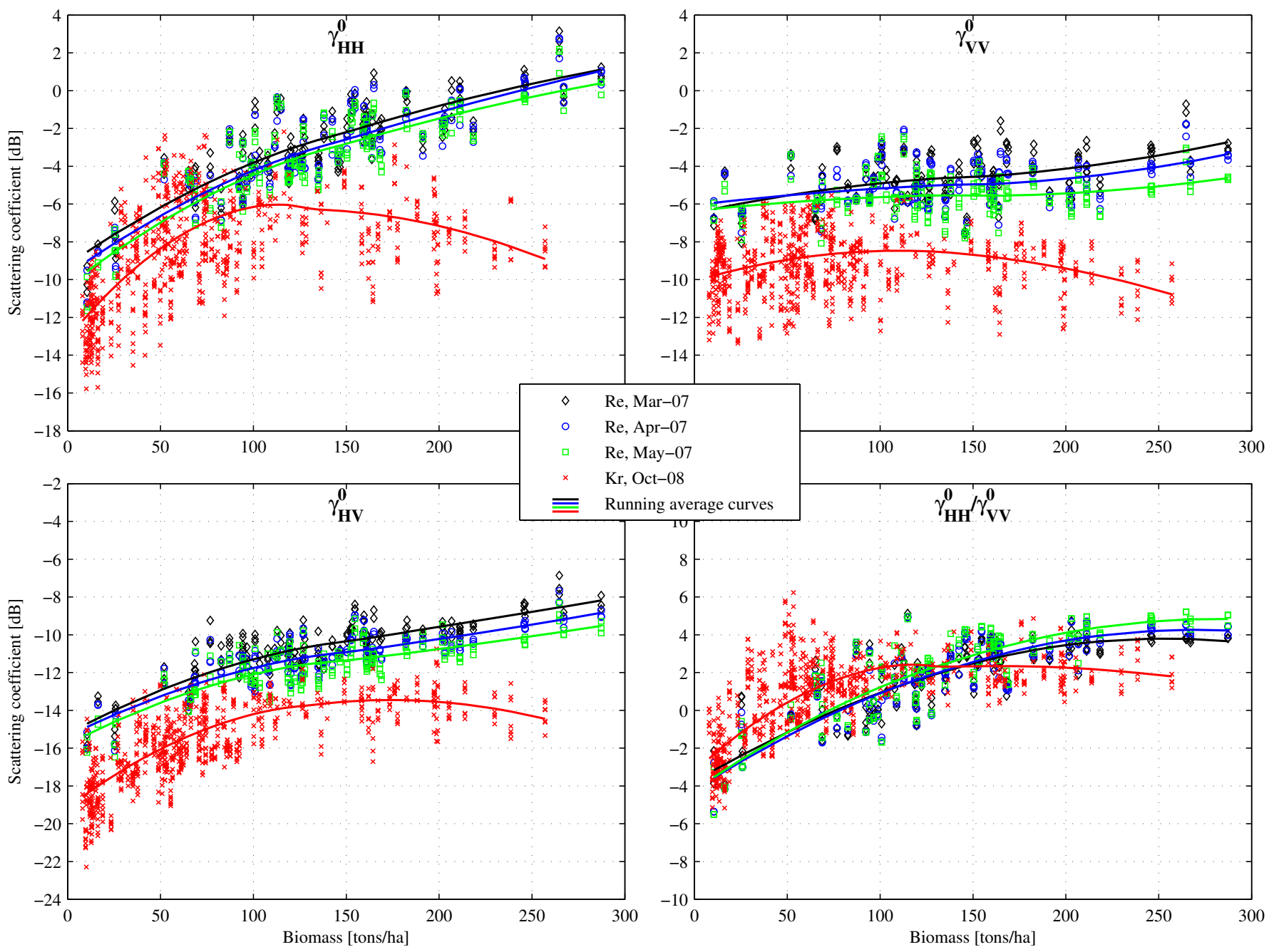

Fig. 4. Backscatter gamma nought for HH, HV and VV, as well as HH/VV backscatter ratio are here plotted in dB for both Krycklan and Remningstorp. Also, the HH/VV-ratio is here plotted in dB. Data points are plotted in different colours and markers if they represent different acquisition time and site. Four running average curves are also plotted to simplify trend investigation. Their colours correspond to the colours of the data points. The grid spacing in $y$-direction is $2 \mathrm{~dB}$ in all four plots.

When trying to define a model suitable for both Remningstorp and Krycklan, the five points mentioned above need to be taken into consideration. It is apparent that biomass retrieval from one curve fitted to all (or parts of) the data may often give very poor results when applied on (parts of) the rest of the data.

One possible way to avoid the aforementioned problems is by finding a biomass indicator less susceptible to temporal and topographic variations. This can be partly achieved by using the ratio of HH- and VV-backscatter, the co-polar ratio. This observable has been plotted against biomass in the bottom plot to the right in Fig. 4. By creating the HH- to VV-backscatter ratio, common factors are eliminated. Biophysical forest parameters such as forest structure, ground surface roughness, and moisture will to some degree have similar impact on both $\mathrm{HH}$ and VV, and their contribution in biomass estimation can be decreased by the use of HH/VV-ratio. Whereas the temporal and site-to-site change has been reduced, the variability is still high. Therefore, instead of using the ratio on its own, it will be combined with HV-backscatter, which has previously shown the most consistent correlation with biomass [38], at least in areas with modest topographic variations.

As mentioned, the influence of topography has been decreased by the inclusion of the HH/VV-ratio, but not fully suppressed. A complementary way of improving the retrieval is by finding a way to compensate for topographic variations using explicit functions, derived either from experimental data, from models, or from both.

An additional important factor to be considered is the number of regression parameters. With too many regression parameters (too many predictors), the risk of overfitting increases, and the model may lack generality. Moreover, the demand on training data increases as more points are needed for stable fitting. On the other hand, with too few regression parameters, the chosen predictors may not be sufficient for accurate modelling. It is thus important to optimise the number of model parameters. 


\section{B. Basic Model}

The first approach for a biomass retrieval model is based on a linear function of backscatter in three polarisation channels (based on [11], [14]-[16]):

$$
\begin{gathered}
\widehat{\mathcal{W}}_{\mathrm{M} 1}=a_{0}+a_{1}\left[\gamma_{\mathrm{HV}}^{0}\right]_{\mathrm{dB}}+ \\
+a_{2}\left[\gamma_{\mathrm{HH}}^{0}\right]_{\mathrm{dB}}+a_{3}\left[\gamma_{\mathrm{VV}}^{0}\right]_{\mathrm{dB}}
\end{gathered}
$$

where $a_{0}$ to $a_{3}$ are model parameters and $\gamma_{\mathrm{PQ}}^{0}$ is the normalised scattering coefficient gamma nought for polarisation PQ. The model (M1) makes use of three observables, and thus four parameters need to be estimated. The results show, that $a_{3}$ has very high uncertainty making $\gamma_{\mathrm{VV}}^{0}$ not suitable for retrieval (as already observed in Fig. 4). Furthermore, earlier studies indicate that a model based on both $\mathrm{HH}$ and $\mathrm{HV}$ may not be significantly better than one based on HV alone [15]. Thus, a simpler model using only one polarisation will be evaluated (also used in [38]):

$$
\widehat{\mathcal{W}}_{\mathrm{M} 2}=a_{0}+a_{1}\left[\gamma_{\mathrm{HV}}^{0}\right]_{\mathrm{dB}} \text {. }
$$

Following the observations about the co-polar ratio made in Fig. 4 and Sec. III-A, i.e. setting

$$
a_{3}=-a_{2},
$$

in (M1), a new model including the HH/VV-ratio is constructed:

$$
\widehat{\mathcal{W}}_{\mathrm{M} 3}=a_{0}+a_{1}\left[\gamma_{\mathrm{HV}}^{0}\right]_{\mathrm{dB}}+a_{2}\left(\left[\gamma_{\mathrm{HH}}^{0}\right]_{\mathrm{dB}}-\left[\gamma_{\mathrm{VV}}^{0}\right]_{\mathrm{dB}}\right),
$$

which makes use of all three observables but only three parameters need to be estimated. A similar model was presented in [11].

\section{New Model with Topographic Correction}

Although the topographic correction introduced in [4], [28] has shown good results at VHF-band, its functional form is too complicated for this work. Instead, a different approach is chosen. In order to find one single, most important topographic indicator, the following functions relating biomass to the two observables $\mathrm{HV}$ and HH/VV-ratio were fitted to the experimental data:

$$
\begin{aligned}
& \widehat{\mathcal{W}}_{1}=C_{1,0}+C_{1,1}\left[\gamma_{\mathrm{HV}}^{0}\right]_{\mathrm{dB}}, \\
& \widehat{\mathcal{W}}_{2}=C_{2,0}+C_{2,1}\left(\left[\gamma_{\mathrm{HH}}^{0}\right]_{\mathrm{dB}}-\left[\gamma_{\mathrm{VV}}^{0}\right]_{\mathrm{dB}}\right),
\end{aligned}
$$

being the two main elements of (M3). $\widehat{\mathcal{W}}_{1}$ and $\widehat{\mathcal{W}}_{2}$ are related to biomass according to (2). The experimental data were divided into smaller groups with similar ground slope, and the fitting was done separately for each group. This way, each model parameter could be studied against the mean value of the topographic indicator for each group.

Four topographic indicators were considered in this study: the local incidence angle $\theta_{i}$, the difference between local and nominal incidence angles $\theta_{i}-\theta_{0}$, the surface slope angle $u$, and the surface slope direction angle $v$. Although this study was done for all four indicators, the most conclusive results of this study, as well as the best biomass retrieval results, were achieved using $u$-based topographic correction.
Therefore, only the results from that part of the study are presented below.

In first row of plots in Fig. 5, the results from grouping by similar surface slope angle $u$ are shown in three plots. The data points used here consisted of $L I D$-stands from Krycklan with upper biomass limit set to 120 tons/ha. This limit was introduced to allow as uniform biomass-slope distribution as possible (see Fig. 6). The number of groups varies between 4 (to the left), 6 (in the middle), and 8 (to the right). Each group has approximately the same number of members. For each stand, the mean backscatter coefficient from four headings was used to reduce the variability due to different angles $v$.

In the second and third rows of plots in Fig. 5, the values of the second parameters $C_{1,1}$ and $C_{2,1}$ in (7) and (8) are plotted against $u$ for three grouping setups. The constant parameters $C_{1,0}$ and $C_{2,0}$ depend not only on $u$, but also on other effects that cannot be predicted from the observables. They are thus not studied here. Whereas $C_{1,1}$ appears to be difficult to relate to $u$ with a simple function, $C_{2,1}$ shows a more clear dependence on $u$. The first approximation of this dependence is a linear function, which suggests an additional term in (M3) consisting of the product of the surface slope $u$ and the HH/VV-ratio:

$$
\begin{aligned}
\widehat{\mathcal{W}}_{\mathrm{M} 4}= & a_{0}+a_{1}\left[\gamma_{\mathrm{HV}}^{0}\right]_{\mathrm{dB}}+a_{2}\left(\left[\gamma_{\mathrm{HH}}^{0}\right]_{\mathrm{dB}}-\left[\gamma_{\mathrm{VV}}^{0}\right]_{\mathrm{dB}}\right)+ \\
& +a_{3} \cdot u\left(\left[\gamma_{\mathrm{HH}}^{0}\right]_{\mathrm{dB}}-\left[\gamma_{\mathrm{VV}}^{0}\right]_{\mathrm{dB}}\right) .
\end{aligned}
$$

\section{Reference Models}

As reference, models presented in previous works by other researchers will be used. First, a single polarisation model:

$$
\widehat{\mathcal{W}}_{\mathrm{R} 1}=C_{0}+C_{1}\left(\left[\gamma_{\mathrm{HV}}^{0}\right]_{\mathrm{dB}}-b_{0}\right) \text {, }
$$

with constants $C_{0}=3.8914$ and $C_{1}=0.1301$ as presented in [54]. The parameter $b_{0}$ is not explicitly included in [54], but is needed, and can be estimated from training data. Note, that (R1) is a simplified version of (M2) with constant slope $\left(a_{1}=C_{1}\right.$ and $\left.a_{0}=C_{0}-C_{1} \cdot b_{0}\right)$.

Also, a seven-parameter model is used [14]:

$$
\begin{aligned}
\widehat{\mathcal{W}}_{\mathrm{R} 2}=a_{0}+ & a_{1}\left[\sigma_{\mathrm{HV}}^{0}\right]_{\mathrm{dB}}+a_{2}\left[\sigma_{\mathrm{HV}}^{0}\right]_{\mathrm{dB}}^{2}+ \\
& +a_{3}\left[\sigma_{\mathrm{HH}}^{0}\right]_{\mathrm{dB}}+a_{4}\left[\sigma_{\mathrm{HH}}^{0}\right]_{\mathrm{dB}}^{2}+ \\
& +a_{5}\left[\sigma_{\mathrm{VV}}^{0}\right]_{\mathrm{dB}}+a_{6}\left[\sigma_{\mathrm{VV}}^{0}\right]_{\mathrm{dB}}^{2}
\end{aligned}
$$

In [14], a more advanced model including topographic corrections was also presented and proved suitable for biomass retrieval from P-band SAR data acquired with the AirSAR platform over the Yellowstone National Park. However, that model was not used in this study because a comparison with (R2) showed that the latter model was in fact more suitable for BioSAR data, and also had fewer parameters ( 7 instead of 14). Note, that in (R2), $\sigma^{0}$ is used instead of $\gamma^{0}$.

\section{MOdEL VALIDATION AND Discussion}

In this section, the models presented in Sec. III will first be tested on data sets from Remningstorp to evaluate the influence of temporal change, mainly in terms of moisture conditions (Sec. IV-B). Thereafter, the models will be tested on data 

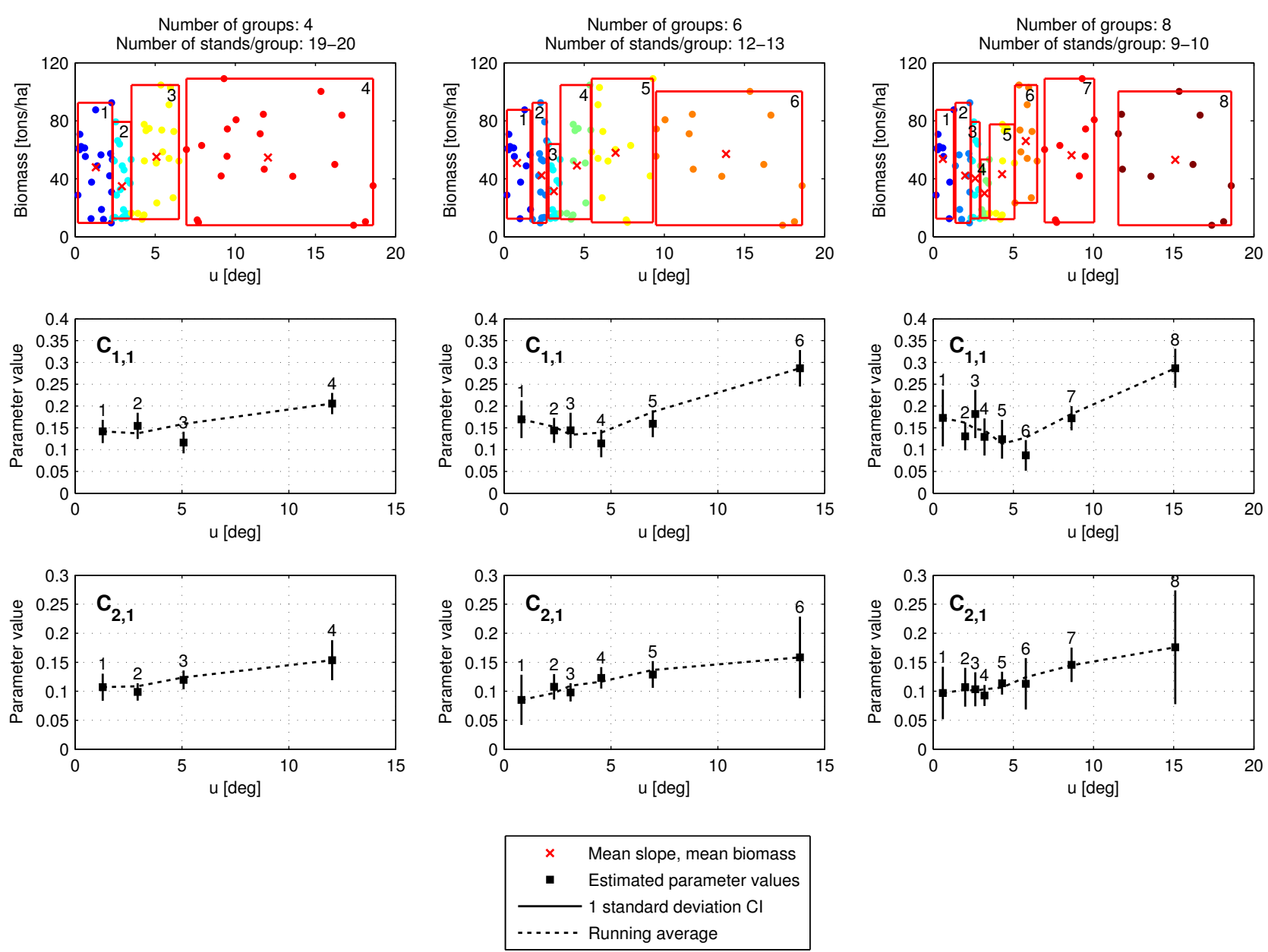

Fig. 5. Results of topographic investigation on LID-stands from Krycklan with upper biomass limit of 120 tons/ha. The topmost row of plots shows clustering of the data points in groups with similar $u$-angle for three grouping setups (4, 6 , and 8 groups with similar number of data points). The groups are delineated with red bounding boxes showing the variability in $u$ and biomass of each group. The red crosses represent the mean slope-mean biomass points for each group. Each group has a number appointed to it in the upper right corner of the corresponding bounding box. The second and third rows of plots show how the second parameter of the fitted models varies with $u$ for two models. Running average curves are shown for easier trend investigation. One standard deviation confidence intervals for the estimated parameters are also shown.

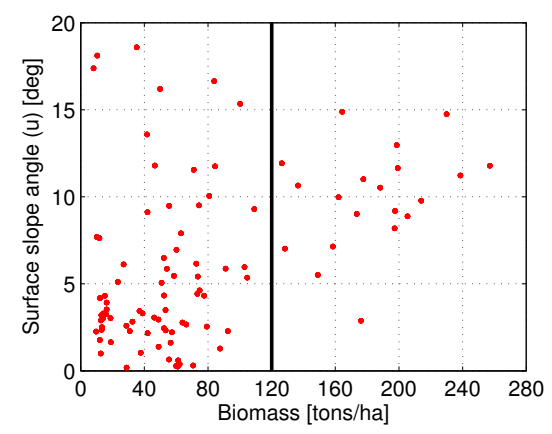

Fig. 6. The distribution of biomass and surface slope for all $91 L I D$-stands in Krycklan. Note, that above approximately 120 tons/ha, most stands are located in sloping terrain. The black line indicates the upper biomass limit for the stands used during the parameter study described in Sec. III-C.

sets from Krycklan to evaluate the influence of topography
(Sec. IV-C). In Sec. IV-D, the models will be evaluated across sites, i.e. models with parameters fitted to one test site will be used for biomass retrieval in the other test site. Next, in Sec. IV-E model errors will be studied against biomass for the three models that showed the best performance in the first three tests. Finally, in Sec. IV-F biomass maps will be produced using the best model, and mapping errors will be pointed out and discussed.

Define the estimation error as:

$$
\widehat{R}(i)=\widehat{\mathcal{B}}(i)-\mathcal{B}_{\text {ref }}(i)
$$

where $\widehat{\mathcal{B}}(i)$ is the estimated biomass using SAR observation $i$, $\mathcal{B}_{\text {ref }}(i)$ is the corresponding reference biomass. Note, that one single observation index $i$ sweeps both through all stands and all acquisitions. The accuracy of the models will be evaluated using several quantitative measures. 
- Root-mean-square error (RMSE) is defined as:

$$
\mathrm{RMSE}=\sqrt{\frac{1}{N} \sum_{i} \widehat{R}(i)^{2}},
$$

where $N$ is the total number of observations.

- Bias is defined as the mean of the estimation error:

$$
\text { bias }=\frac{1}{N} \sum_{i} \widehat{R}(i) \text {. }
$$

With this notation, positive bias means overestimation, and negative bias means underestimation.

- Standard deviation of the estimation error can be computed from (10) and (11) as:

$$
\text { standard deviation }=\sqrt{(\mathrm{RMSE})^{2}-(\mathrm{bias})^{2}} \text {. }
$$

- The coefficient of determination $R^{2}$ is a measure of how well a linear model fits the data in comparison with a simple average [55]. It is computed according to:

$$
R^{2}=1-\frac{\sum_{i}\left(\mathcal{B}_{\text {ref }}(i)-\widehat{\mathcal{B}}(i)\right)^{2}}{\sum_{i}\left(\mathcal{B}_{\text {ref }}(i)-\overline{\mathcal{B}}_{\text {ref }}\right)^{2}},
$$

where

$$
\overline{\mathcal{B}}_{\text {ref }}=\frac{1}{N} \sum_{i} \mathcal{B}_{\text {ref }}(i)
$$

is the mean reference biomass. For accurate modelling, $R^{2}$ should be as close to one as possible. Values below zero indicate that better modelling results would be achieved with an average of the reference data.

- The relative error is defined as:

$$
\text { relative error }=100 \% \cdot \frac{\widehat{\mathcal{B}}-\mathcal{B}_{\text {ref }}}{\mathcal{B}_{\text {ref }}} \text {. }
$$

\section{A. Data Selection and Model Training}

Since the model performance depends on the reliability of model parameter estimation (model training), the choice of the data used for training demands care.

First, the training data need to cover a large parameter range and have a reasonable accuracy. Lidar-based measurements present a good compromise between accuracy and coverage. Therefore, $L I D$-stands presented in Table II will be used as training data.

The number of SAR measurements is not equal for all stands, and not all stands are always covered (see Table III). Also, in some cases more than one geocoded SAR image is available for each scenario (same site, same imaging geometry, same acquisition date). A bias problem may thus occur. To minimise that problem, only one measurement per stand from each site, each date, and each heading was chosen to be used, and only the $L I D$-stands covered by all images were used for training.

In Remningstorp, two geocoded images with zero nominal baseline were available for each acquisition date at the 200degree heading. Since no systematic differences could be observed in the stand-wise data between the two acquisitions, the second acquisition specified in Table III was arbitrarily chosen.
In case of the two headings $134^{\circ}$ and $314^{\circ}$ in Krycklan, for which multiple images were available, the choice was made to maximise the number of covered stands. The following images were therefore used:

\section{- Remningstorp:}

- heading $179^{\circ}$ : one image for each date $(\underline{0110}, \underline{0206}$, and 0412 ),

- heading $200^{\circ}$ : one image for each date $(\underline{0109}, \underline{0306}$, and 0411 ).

\section{- Krycklan:}

- heading $43^{\circ}$ : one image (0304),

- heading $134^{\circ}$ : one image (0104),

- heading $314^{\circ}$ : one image ( $\left.\underline{0103}\right)$,

- heading $358^{\circ}$ : one image (0301).

The underlined numbers in parentheses refer to the identification numbers of each image, as shown in Table III and in [44], [45].

In total, Remningstorp data suitable for training were limited to a maximum of $46 L I D$-stands (out of 58) and 6 acquisitions for each stand (out of 9, see Table III). For Krycklan, data suitable for training were limited to a maximum of 97 $L I D$-stands and 4 acquisitions for each stand (out of 7 , see Table III). Note, that in many cases, smaller subsets of these data sets were used for training. In cases when more than one acquisition per stand was used, different observations in the training data set were not entirely independent of each other, which might cause problems in the statistical analysis. In Sec. IV-E, this issue is pointed out and discussed.

Since all the models used in this text are linear, least-squares as implemented in Matlab function regress was used for parameter estimation.

For best quantitative validation, high-accuracy $I N S$-stands were used. For temporal validation in Remningstorp, the same restrictions as for training data applied to validation data in order to be able to make fair comparison between headings. For the other validation scenarios, all available SAR acquisitions for each stand were used for biomass prediction, giving up to 9 biomass values for some stands in Remningstorp and up to 7 biomass values for some stands in Krycklan. This approach increases the influence of the well-represented stands during validation.

\section{B. Temporal Validation}

In this part, the models were trained using $L I D$-stands in Remningstorp and validated using $I N S$-stands from the same test site. Only the stands fully covered by both 179and 200-degree acquisitions were used. Each combination of dates was examined, as well as the results of training and validation on all three dates. Root-mean-square errors (RMSE) are presented in Table $\mathrm{V}$ in tons/ha together with the coefficients of determination $R^{2}$. The mean biomass for validation data is 181 tons/ha. In this comparison, model (M4) was not included since topography is not significant in Remningstorp.

Looking at same date retrieval (training and validation on the same date), all models show reasonable performance with root-mean-square errors ranging between 35 and 60 tons/ha 
TABLE IV

PARAMETER VALUES FOR THE SIX TESTED MODELS. TRAINING DATA CONSISTS OF ALL AVAILABLE LID-STANDS IN RESPECTIVE TEST SITE COVERED BY EXACTLY ONE IMAGE FROM EACH HEADING AND EACH DATE, SEE SEC. IV-A. THE PARAMETERS WRITTEN IN ITALICS WERE FOUND VERY UNCERTAIN (THEIR UNCERTAINTY INTERVALS INCLUDE ZERO).

\begin{tabular}{|l|ll|}
\hline Model: & \multicolumn{1}{|c|}{ Parameters estimated in Remningstorp } \\
\hline (R1) & $b_{0}=2.827 \pm 0.138$ & \\
\hline (R2) & $a_{0}=0.842 \pm 0.650$ & $a_{1}=0.065 \pm 0.022$ \\
& $a_{2}=-0.206 \pm 0.111$ & $a_{3}=-0.122 \pm 0.094$ \\
& $a_{4}=-0.001 \pm 0.002$ & $a_{5}=-0.010 \pm 0.004$ \\
& $a_{6}=-0.006 \pm 0.007$ & \\
\hline (M1) & $a_{0}=2.886 \pm 0.146$ & $a_{1}=0.078 \pm 0.016$ \\
& $a_{2}=0.072 \pm 0.010$ & $a_{3}=-0.056 \pm 0.015$ \\
\hline (M2) & $a_{0}=3.632 \pm 0.136$ & $a_{1}=0.140 \pm 0.012$ \\
\hline (M3) & $a_{0}=2.933 \pm 0.138$ & $a_{1}=0.089 \pm 0.011$ \\
& $a_{2}=0.068 \pm 0.009$ & \\
\hline (M4) & $a_{0}=2.967 \pm 0.137$ & $a_{1}=0.093 \pm 0.011$ \\
& $a_{2}=0.056 \pm 0.011$ & $a_{3}=0.713 \pm 0.411$ \\
\hline & \multicolumn{3}{|c|}{ Parameters estimated in Krycklan } \\
\hline Model: & \multicolumn{3}{|c|}{} \\
\hline (R1) & $b_{0}=0.766 \pm 0.190$ & $a_{1}=0.029 \pm 0.059$ \\
\hline (R2) & $a_{0}=2.507 \pm 1.246$ & $a_{3}=-0.105 \pm 0.115$ \\
& $a_{2}=0.061 \pm 0.144$ & $a_{5}=-0.002 \pm 0.004$ \\
& $a_{4}=-0.001 \pm 0.003$ & $a_{1}=0.093 \pm 0.013$ \\
& $a_{6}=0.001 \pm 0.005$ & $a_{3}=0.605 \pm 0.134$ \\
\hline (M1) & $a_{0}=3.280 \pm 0.203$ & $a_{3}=-0.113 \pm 0.016$ \\
& $a_{2}=0.049 \pm 0.012$ & $a_{1}=0.149 \pm 0.012$ \\
\hline (M2) & $a_{0}=4.087 \pm 0.191$ & $a_{1}=0.109 \pm 0.013$ \\
\hline (M3) & $a_{0}=3.402 \pm 0.222$ & \\
& $a_{2}=0.063 \pm 0.013$ & $a_{0}$ \\
\hline (M4) & $a_{0}=3.129 \pm 0.211$ & \\
& $a_{2}=0.020 \pm 0.015$ & \\
\hline
\end{tabular}

(19-32\% of mean biomass). However, as the retrieval scenario becomes more difficult, and the training and validation dates are further apart, the single polarisation models (R1) and (M2) often show significantly higher errors compared to models including all polarisations.

Comparing the two headings (and keeping in mind that the 179-degree heading features steeper incidence angles) it can be observed that for models (R1) and (M2), the retrieval is more stable across dates for the 179-degree heading (however, it gives in general worse results). Moreover, the data set used for training seems to affect the results much more for the 179-degree heading than for the 200-degree heading, for which only the temporal distance between training and validation data seems of an importance (the error is lowest on the diagonal and higher off-diagonal). This is clearly visible for models (M1) and (M3) at the 179-degree heading, where training on May data gives RMSE around 40 tons/ha, no matter which date is used for validation. For training on April data, the same values lie over 60 tons/ha.

Also when trained and validated using all temporal acquisitions, full polarisation models (R2), (M1), and (M3) show better results, especially for the 200-degree heading with retrieval error as low as 39 tons/ha $(21 \%)$.

It can be observed here that (R1) often performs better than (M2) in spite of the fact that it has one parameter instead of two, but otherwise the same structure. This is an indication of possible overfitting with (M2). Model (R1) was if fact developed from (M2) using data sets from several different test sites and campaigns (both tropical and boreal). As the estimates of the slope parameter in (M2) were found consistent for these data sets, the slope could be set to a constant. Almost all performance analysis in this paper is done using independent training and validation sets, which helps to detect overfitting.

\section{Topographic Validation}

In this part, the models were trained and validated using different heading combinations in Krycklan. The RMSE and $R^{2}$ are shown for all training-validation combinations in Table VI. The mean biomass level for Krycklan $I N S$-stands is 95 tons/ha. The models which include all three polarisations, (R2), (M1), (M3), and (M4), show slightly better performance than the two single polarised models (R1) and (M2), but the improvement is small. Perhaps surprisingly, the correction in (M4) does not improve the retrieval results in this case because the variability in backscatter from one stand is not reduced by the model (since only the slope angle $u$ is included in the model and this angle is constant for all acquisition geometries).

In general, all models give errors higher than approximately $28 \%$ (26 tons/ha). Validation results are more conclusive for the two main headings $\left(134^{\circ}\right.$ and $\left.314^{\circ}\right)$ because the number of validation points is 27 and 28, compared to 9 and 10 for the other two headings. Also, the distribution of slopes for different biomass levels is nonuniform in the training data. The high-biomass stands are situated in sloping terrain, see Fig. 6.

\section{Across-Site Validation}

The across-site test was done in two steps: training in Remningstorp and validation in Krycklan, and vice versa. These two tests will be evaluated separately.

1) Flat-to-Topographic: A problem occurs when the models are trained using Remningstorp data and validated using Krycklan data: Remningstorp data do not include enough topographic variations for reliable training; the retrieval models perform poorly if only Remningstorp data are used, see Table VII. Retrieval errors are at minimum 37\% (35 tons/ha), but the variability of the data is large, and the coefficient of determination is low. In terms of RMSE, model (M4) performs best here. However, $R^{2}$-values are low.

In Fig. 7, scatter plots showing estimation results for all six models are shown. Acquisitions from all three dates and both headings in Remningstorp were used for training (model parameters as in Table IV). Retrieval results for all Krycklan data are shown in the plots, in red for $L I D$-stands and in black for $I N S$-stands. For all models except (M4), biomass in Krycklan is underestimated. For (M4), the variability in data is larger compared to the rest of the models, but the bias is reduced.

2) Topographic-to-Flat: Here, LID data from the topographic area of Krycklan, featuring a variety of stands in different slope conditions, were used for training of the models. In Table VIII, the resulting RMSE values are shown together with the coefficient of determination $R^{2}$. The mean biomass for Remningstorp $I N S$-stands is 181 tons/ha. It can be observed that retrieval errors as low as $22 \%$ (40 tons/ha) can be achieved 
TABLE V

RESULTS OF TEMPORAL VALIDATION OF MODELS $1-5$ IN TERMS OF RMSE (TONS/HA, FIRST ROW) AND $R^{2}$ (SECOND ROW). COLOUR CODING BY RMSE RELATIVE MEAN BIOMASS (181 TONS/HA): WHITE FOR $20 \%$ AND BELOW, BLACK FOR $100 \%$ AND ABOVE.

\begin{tabular}{|c|c|c|c|c|c|c|c|c|c|c|c|c|c|c|c|}
\hline Model: & \multicolumn{3}{|c|}{ R1 } & \multicolumn{3}{|c|}{$\mathrm{R} 2$} & \multicolumn{3}{|c|}{ M1 } & \multicolumn{3}{|c|}{ M2 } & \multicolumn{3}{|c|}{ M3 } \\
\hline & \multicolumn{7}{|c|}{ Heading: $179^{\circ}$} & \multicolumn{8}{|c|}{ TRAINING } \\
\hline & Mar & Apr & May & Mar & Apr & May & Mar & Apr & May & Mar & Apr & May & Mar & Apr & May \\
\hline \multirow{2}{*}{ Mar } & $\mathbf{5 0}$ & 61 & 71 & 42 & 46 & 82 & 55 & 84 & 41 & 55 & 89 & 85 & 51 & 78 & 38 \\
\hline & 0.43 & 0.14 & -0.16 & 0.6 & 0.53 & -0.53 & 0.32 & -0.59 & 0.61 & 0.31 & -0.81 & -0.67 & 0.4 & -0.4 & 0.66 \\
\hline \multirow{2}{*}{ Apr } & 65 & 53 & 52 & 41 & 39 & 71 & 49 & 65 & 41 & 64 & 59 & 56 & 47 & 59 & 39 \\
\hline & 0.04 & 0.37 & 0.39 & 0.62 & 0.65 & -0.16 & 0.44 & 0.05 & 0.62 & 0.07 & 0.21 & 0.3 & 0.5 & 0.21 & 0.66 \\
\hline \multirow{3}{*}{ May } & 75 & 58 & 53 & 32 & 31 & 48 & 43 & 60 & 37 & 73 & 57 & 53 & 43 & 60 & 37 \\
\hline & -0.27 & 0.23 & 0.35 & 0.76 & 0.78 & 0.47 & 0.57 & 0.17 & 0.68 & -0.22 & 0.26 & 0.35 & 0.58 & 0.17 & 0.69 \\
\hline & \multicolumn{3}{|c|}{ All } & \multicolumn{3}{|c|}{ All } & \multicolumn{3}{|c|}{ All } & \multicolumn{3}{|c|}{ All } & \multicolumn{3}{|c|}{ All } \\
\hline All & \multicolumn{3}{|c|}{$\begin{array}{c}58 \\
0.24\end{array}$} & \multicolumn{3}{|c|}{$\begin{array}{c}44 \\
0.55\end{array}$} & \multicolumn{3}{|c|}{$\begin{array}{c}50 \\
0.43\end{array}$} & \multicolumn{3}{|c|}{$\begin{array}{c}60 \\
0.19\end{array}$} & \multicolumn{3}{|c|}{$\begin{array}{c}46 \\
0.51\end{array}$} \\
\hline
\end{tabular}

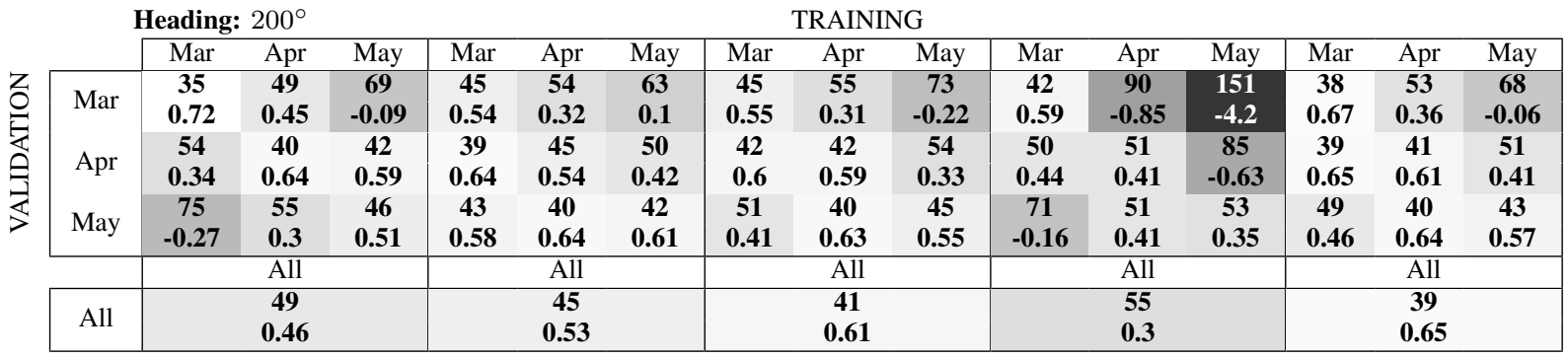

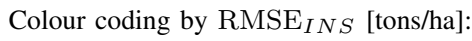

$\leq 36$

181

TABLE VI

RESULTS OF TOPOGRAPHIC VALIDATION OF MODELS 1-6 IN TERMS OF RMSE (TONS/HA) AND $R^{2}$ (IN PARENTHESES). COLOUR CODING BY RMSE RELATIVE MEAN BIOMASS (95 TONS/HA): WHITE FOR $20 \%$ AND BELOW, BLACK FOR $100 \%$ AND ABOVE.

\begin{tabular}{|c|c|c|c|c|c|c|}
\hline Model: & $\mathrm{R} 1$ & $\mathrm{R} 2$ & M1 & M2 & M3 & M4 \\
\hline & \multicolumn{6}{|c|}{ TRAINING HEADING: $43^{\circ}$} \\
\hline $43^{\circ}$ & $36(0.37)$ & $30(0.56)$ & $30(0.58)$ & $34(0.45)$ & $31(0.55)$ & $33(0.48)$ \\
\hline $134^{\circ}$ & $35(0.31)$ & $31(0.48)$ & $29(0.53)$ & $37(0.23)$ & $29(0.52)$ & $33(0.39)$ \\
\hline $314^{\circ}$ & $35(0.26)$ & $36(0.22)$ & $31(0.42)$ & $37(0.19)$ & $34(0.34)$ & $37(0.2)$ \\
\hline $358^{\circ}$ & $40(0.3)$ & $32(0.55)$ & $32(0.56)$ & $40(0.32)$ & $38(0.37)$ & $39(0.36)$ \\
\hline All & $36(0.3)$ & $33(0.41)$ & $30(0.5)$ & $37(0.25)$ & $32(0.45)$ & $35(0.34)$ \\
\hline
\end{tabular}

\begin{tabular}{|c|c|c|c|c|c|c|}
\hline $43^{\circ}$ & $43(01)$ & $37(033)$ & $30(0-58)$ & $43(0.11)$ & $30(057)$ & $30(056)$ \\
\hline $134^{\circ}$ & $38(0.18)$ & $31(0.47)$ & $29(0.52)$ & 38 (0.18) & $30(0.51)$ & $30(0.48)$ \\
\hline $314^{\circ}$ & $40(0.07)$ & $35(0.26)$ & $34(0.33)$ & $39(0.08)$ & $35(0.26)$ & $34(0.3)$ \\
\hline $358^{\circ}$ & $45(0.11)$ & $42(0.25)$ & $38(0.36)$ & $45(0.11)$ & $40(0.3)$ & $39(0.35)$ \\
\hline All & $40(0.13)$ & $34(0.36)$ & $32(0.45)$ & $40(0.14)$ & $33(0.41)$ & $33(0.42)$ \\
\hline
\end{tabular}

\begin{tabular}{|c|c|c|c|c|c|c|}
\hline & \multicolumn{6}{|c|}{ TRAINING HEADING: $314^{\circ}$} \\
\hline $43^{\circ}$ & $37(0.35)$ & $31(0.55)$ & $27(0.67)$ & $34(0.46)$ & $26(0.67)$ & $27(0.64)$ \\
\hline $134^{\circ}$ & $35(0.31)$ & $35(0.31)$ & $31(0.47)$ & $44(-0.08)$ & $37(0.25)$ & $28(0.57)$ \\
\hline $314^{\circ}$ & $36(0.25)$ & $29(0.52)$ & $28(0.55)$ & $44(-0.14)$ & $42(-0.03)$ & $30(0.47)$ \\
\hline $358^{\circ}$ & $41(0.29)$ & $31(0.59)$ & $31(0.57)$ & $42(0.25)$ & $42(0.24)$ & $40(0.31)$ \\
\hline All & $36(0.29)$ & $32(0.44)$ & $29(0.53)$ & $43(0)$ & $38(0.2)$ & $30(0.51)$ \\
\hline
\end{tabular}

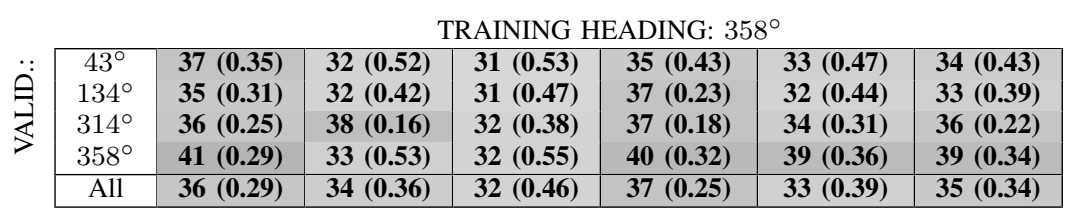

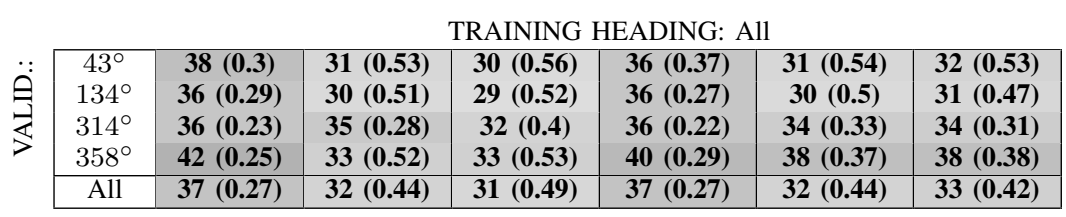

Colour coding by RMSE $I N S$ [tons/ha]: $\quad \leq 19 \quad \geq 95$ 
TABLE VII

RESULTS OF FLAT-TO-TOPOGRAPHIC VALIDATION OF MODELS 1-6 IN TERMS OF RMSE (TONS/HA) AND $R^{2}$ (IN PARENTHESES). COLOUR CODING BY RMSE RELATIVE MEAN BIOMASS (95 TONS/HA): WHITE FOR $20 \%$ AND BELOW, BLACK FOR $100 \%$ AND ABOVE.

\begin{tabular}{|c|c|c|c|c|c|c|}
\hline Model: & R1 & $\mathrm{R} 2$ & M1 & M2 & M3 & M4 \\
\hline & \multicolumn{6}{|c|}{ TRAINING DATA: March, both headings } \\
\hline $43^{\circ}$ & $68(-1.19)$ & $75(-1.69)$ & $62(-0.81)$ & $71(-1.41)$ & $60(-0.69)$ & $48(-0.12)$ \\
\hline $134^{\circ}$ & $63(-1.21)$ & $63(-1.2)$ & $57(-0.79)$ & $66(-1.45)$ & $55(-0.68)$ & $48(-0.29)$ \\
\hline $314^{\circ}$ & $66(-1.55)$ & $68(-1.76)$ & $58(-0.99)$ & $69(-1.81)$ & $57(-0.91)$ & $51(-0.54)$ \\
\hline $358^{\circ}$ & $69(-1.05)$ & $74(-1.39)$ & $61(-0.63)$ & $72(-1.24)$ & $60(-0.53)$ & $51(-0.1)$ \\
\hline All & $65(-1.3)$ & $67(-1.45)$ & $58(-0.83)$ & $68(-1.53)$ & $56(-0.74)$ & $49(-0.33)$ \\
\hline
\end{tabular}

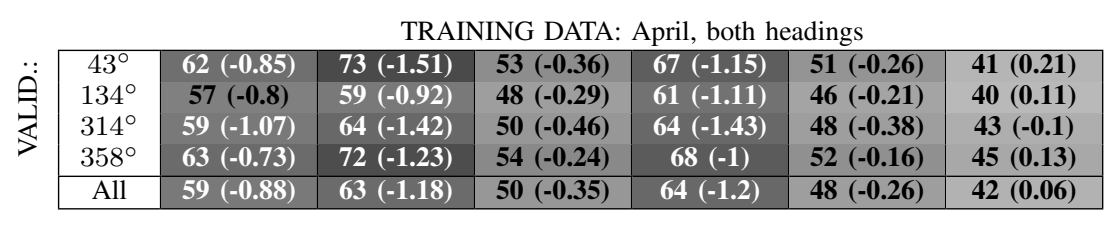

TRAINING DATA: May, both headings

\begin{tabular}{|c|c|c|c|c|c|c|}
\hline $43^{\circ}$ & $59(-0.68)$ & $70(-1.35)$ & $50(-0.18)$ & $64(-0.94)$ & $46(-0.02)$ & $35(0.43)$ \\
\hline $134^{\circ}$ & $54(-0.6)$ & $55(-0.67)$ & $45(-0.11)$ & $58(-0.85)$ & $42(0.02)$ & $35(0.32)$ \\
\hline $314^{\circ}$ & $56(-0.85)$ & $61(-1.2)$ & $46(-0.26)$ & $60(-1.14)$ & $44(-0.14)$ & $38(0.12)$ \\
\hline $358^{\circ}$ & $60(-0.57)$ & $70(-1.1)$ & $51(-0.1)$ & $64(-0.8)$ & $48(0.02)$ & $42(0.23)$ \\
\hline All & $56(-0.68)$ & $60(-0.96)$ & $46(-0.16)$ & $60(-0.94)$ & $44(-0.04)$ & $37(0.26)$ \\
\hline
\end{tabular}

TRAINING DATA: All dates, both headings

\begin{tabular}{|c|c|c|c|c|c|c|}
\hline $43^{\circ}$ & $63(-0.91)$ & $70(-1.36)$ & $53(-0.33)$ & $66(-1.05)$ & $50(-0.2)$ & $38(0.3)$ \\
\hline $134^{\circ}$ & $58(-0.87)$ & $57(-0.8)$ & $48(-0.28)$ & $60(-1.02)$ & $46(-0.16)$ & $38(0.18)$ \\
\hline $314^{\circ}$ & $60(-1.16)$ & $63(-1.31)$ & $49(-0.43)$ & $63(-1.32)$ & $47(-0.33)$ & $42(-0.03)$ \\
\hline $358^{\circ}$ & $64(-0.79)$ & $70(-1.11)$ & $53(-0.22)$ & $66(-0.91)$ & $51(-0.11)$ & $44(0.18)$ \\
\hline All & $60(-0.95)$ & $61(-1.06)$ & $49(-0.32)$ & $62(-1.1)$ & $47(-0.21)$ & $40(0.12)$ \\
\hline
\end{tabular}

Colour coding by RMSE $\operatorname{INS}_{\text {[tons/ha] }} \leq 19 \quad \longleftrightarrow \quad \geq 95$

TABLE VIII

RESULTS OF TOPOGRAPHIC-TO-FLAT VALIDATION OF MODELS 1-6 IN TERMS OF RMSE (TONS/HA) AND $R^{2}$ (IN PARENTHESES). COLOUR CODING BY RMSE RELATIVE MEAN BIOMASS (181 TONS/HA): WHITE FOR $20 \%$ AND BELOW, BLACK FOR $100 \%$ AND ABOVE.

\begin{tabular}{|c|c|c|c|c|c|c|c|}
\hline \multicolumn{2}{|c|}{ Model: } & R1 & R2 & M1 & M2 & M3 & M4 \\
\hline \multirow{5}{*}{ 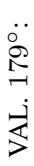 } & & \multicolumn{6}{|c|}{ TRAINING DATA: All headings } \\
\hline & Mar & $>200(-12.25)$ & $56(0.29)$ & $100(-1.28)$ & $>200(-36.78)$ & $>200(-12.37)$ & $59(0.22)$ \\
\hline & Apr & $157(-4.61)$ & $59(0.2)$ & $64(0.05)$ & $>200(-15.8)$ & $180(-6.37)$ & $41(0.61)$ \\
\hline & May & $123(-2.48)$ & $48(0.48)$ & $86(-0.7)$ & $>200(-9.66)$ & $175(-5.98)$ & $41(0.62)$ \\
\hline & All & $181(-6.45)$ & $55(0.32)$ & $85(-0.64)$ & $>200(-20.75)$ & $>200(-8.24)$ & $48(0.48)$ \\
\hline \multicolumn{8}{|c|}{ TRAINING DATA: All headings } \\
\hline \multirow{4}{*}{ 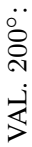 } & Mar & $187(-6.78)$ & $74(-0.22)$ & $68(-0.03)$ & $>200(-21.2)$ & $198(-7.77)$ & $46(0.54)$ \\
\hline & Apr & $137(-3.2)$ & $71(-0.11)$ & $58(0.25)$ & $>200(-11.6)$ & $178(-6.06)$ & $40(0.64)$ \\
\hline & May & $88(-0.73)$ & $62(0.13)$ & $58(0.26)$ & $157(-4.48)$ & $147(-3.78)$ & $41(0.63)$ \\
\hline & All & $143(-3.57)$ & $69(-0.07)$ & $61(0.16)$ & $>200(-12.43)$ & $176(-5.87)$ & $42(0.6)$ \\
\hline \multirow{5}{*}{ 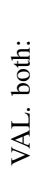 } & & \multicolumn{6}{|c|}{ TRAINING DATA: All headings } \\
\hline & Mar & $>200(-8.42)$ & $69(-0.06)$ & $79(-0.41)$ & $>200(-25.88)$ & $>200(-9.15)$ & $50(0.44)$ \\
\hline & Apr & $144(-3.62)$ & $67(-0.01)$ & $60(0.19)$ & $>200(-12.84)$ & $179(-6.13)$ & $41(0.63)$ \\
\hline & May & $100(-1.26)$ & $58(0.24)$ & $68(-0.03)$ & $177(-6.04)$ & $156(-4.44)$ & $41(0.63)$ \\
\hline & All & $156(-4.43)$ & $65(0.05)$ & $70(-0.08)$ & $>200(-14.92)$ & $184(-6.57)$ & $44(0.57)$ \\
\hline
\end{tabular}


with (M4). Single-polarisation models (R1) and (M2), and model (M3) show all extremely high errors going above $100 \%$ of mean biomass level. This validation scenario shows clearly the advantage of models (R2), (M1), and (M4). For (M4), the $R^{2}$-values are also high, see Table VIII.

In Fig. 8, scatter plots showing estimation results for all six models are shown. Acquisitions from all four headings in Krycklan were used for training (model parameters as in Table IV). Retrieval results for all Remningstorp data are shown in the plots, in blue for $L I D$-stands and in black for $I N S$-stands. For all models except (M4) and (R2), biomass in Remningstorp is overestimated. For (M4), the variability in data is larger compared to (R2), but the bias (underestimation) observed above 200 tons/ha is reduced.

\section{E. Error Analysis}

Looking at the results presented in the previous three sections, it can be observed that models (R2), (M1), and (M4) show best overall performance of the six studied models. Models (M1) and (M4) have the advantage of having less parameters and showing better results in flat-to-topographic retrieval. Although (R2) gives less variability (improved precision) in the higher biomass levels, a loss of sensitivity (reduced accuracy, higher bias) can be observed for biomass values above 200 tons/ha. Whereas the precision of a model can be improved using spatial averaging, it is difficult to improve the accuracy. Therefore, a limited increase in variability is an acceptable trade-off for lower bias.

As mentioned in Sec. IV-A, all observations used for training are not completely independent, since several observations from the same stand but with different imaging geometry and/or acquisition date are used simultaneously for parameter estimation. This breach of independence can be observed in Fig. 4 as clustering of observations from the same stand. This might induce slightly different parameter estimates compared to the estimates, which would be obtained if the full dependence structure of the observations was known. However, since the majority of pairs of observations are independent, these differences are likely to be small. Moreover, small differences in parameter estimates compared to "true" parameter values are not of concern in this study. The main focus of this paper is not the parameter estimation, but rather the performance analysis and the comparison of different models. The only real concern is the estimation of confidence intervals, which will be affected by the presence of unknown correlation between observations.

With the above discussion in mind, some conclusions can nevertheless be drawn from Table IV containing the estimated regression parameters. In particular, some of the coefficients for (R2) are not significantly different from zero (their confidence intervals include zero). This indicates that the model contains too many predictors. Note also, that the parameters of model (M4) are similar for both Remningstorp and Krycklan. This is an indication that the coefficients of this model are stable over a broad range of forest conditions.

In Fig. 9, bias (mean of the estimation error), standard deviation of the estimation error, and RMSE are plotted against biomass for models (R2), (M1), and (M4). These quantities have been defined in (10)-(12). For this study, the model parameters were those specified in Table IV. Statistics were computed for $L I D$-stands in both Remningstorp and Krycklan, and the averaging was done in three intervals: low biomass (0-100 tons/ha), medium biomass (100-200 tons/ha), and high biomass (200-300 tons/ha).

It can be observed that all three models perform almost equally well when both trained and evaluated in Remningstorp (solid lines in the top three plots in Fig. 9). Model (R2) shows higher bias in the high-biomass group (underestimation with approximately 40 tons/ha), but the variability is quite small (standard deviation up to 30 tons/ha). When training and validation are both done in Krycklan (solid lines in the bottom three plots in Fig. 9), one can observe a strong underestimation occurring for stands with biomass above 100 tons/ha and a high variability. The origin of this bias can probably be related to the nonuniform biomass-slope distribution mentioned earlier and shown in Fig. 6, but a clear conclusion is difficult to be made as the number of independent data points is low. Also, the fact that none of the models compensates for variability with angle $v$ contributes to the observed large variability. All three models perform similarly.

It is during across-site validation that (M4) proves itself better than the other two models. Lower bias is observed when training on Remningstorp and applying to Krycklan (dashed lines in the bottom three plots in Fig. 9). In the opposite case, (R2) shows lower bias for low-biomass stands, but higher in the two other groups (dashed lines in the top three plots in Fig. 9). Although (M4) shows in some cases slightly higher standard deviation of residuals, this effect can be reduced by spatial averaging. Bias is more difficult to reduce and should thus be kept as low as possible. Altogether, (M4) is observed as the best of the six models examined in this paper. Note, that in Krycklan, there is a lack of stands with high biomass and low slopes, whereas in Remningstorp these types of stands are common. An extrapolation is made for such stands when the model (M4) is trained in Krycklan and evaluated in Remningstorp. The exact influence of this effect on the retrieval is unclear.

\section{F. Biomass Mapping Performance Analysis}

In order to evaluate mapping performance of the new model, biomass maps were created from SAR images using (M4). In Fig. 10, a set of biomass maps is shown. To the left, biomass maps based on lidar scanning are shown. In the middle and to the right, two biomass maps extracted from SAR using (M4) are shown. For both Remningstorp and Krycklan, the same SAR images as used for training were used (those described in Sec. IV-A, 6 images for Remningstorp and 4 images for Krycklan). Geocoded images with pixel size $2 \mathrm{~m} \times 2 \mathrm{~m}$ were first filtered using an average filter with a $5 \times 5$ window to match the resolution of the lidar-based biomass maps. Next, the filtered SAR images were re-sampled using linear interpolation to the same grid as the lidar-based biomass maps $(10 \mathrm{~m} \times 10 \mathrm{~m})$. Thereafter, all biomass maps were filtered with a $7 \times 7$ average filter in order to reduce resolution to 
R1
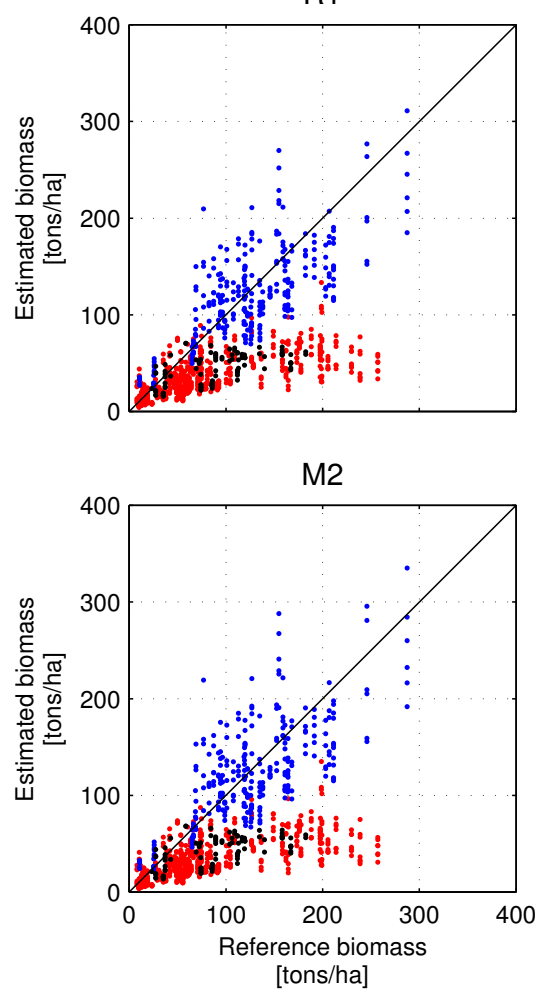

R2
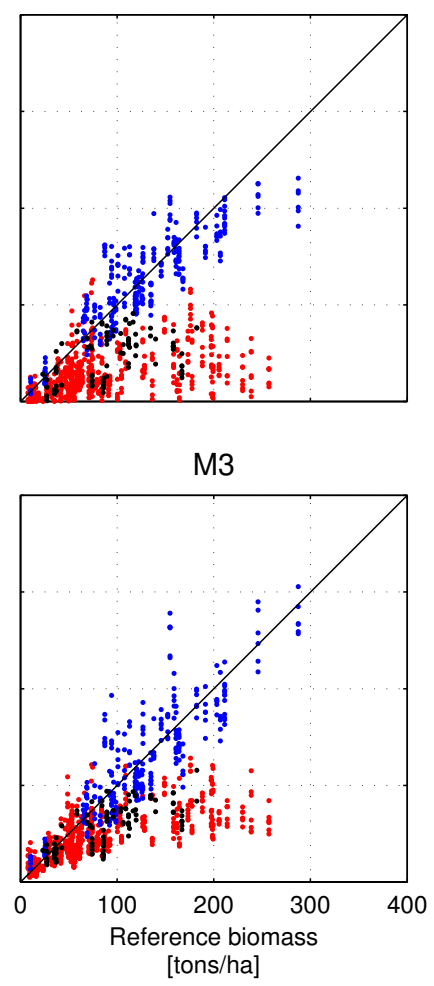

M1
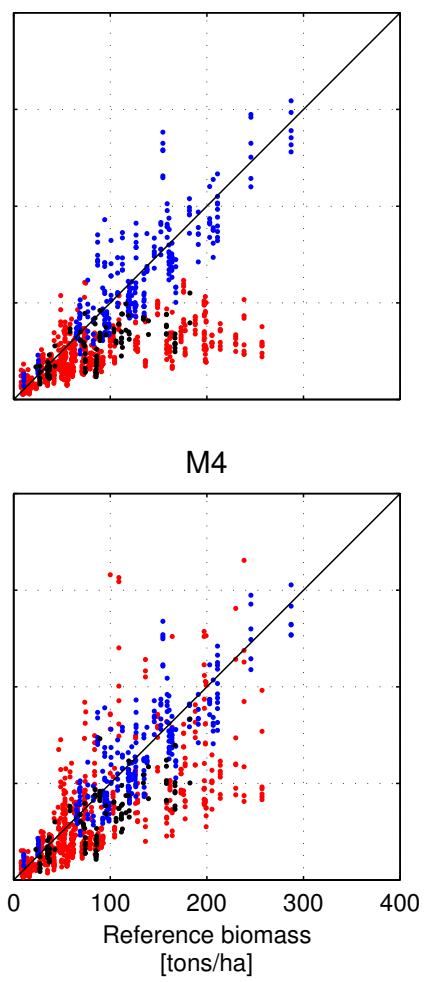

Parameters from

Remningstorp

(all dates,

both headings)

Retrieval results:

- $\mathrm{Re}, \mathrm{LID}$

- $\mathrm{Kr}, \mathrm{LID}$

- $\mathrm{Kr}$, INS

Fig. 7. Comparison of the six evaluated models: training on Remningstorp data.
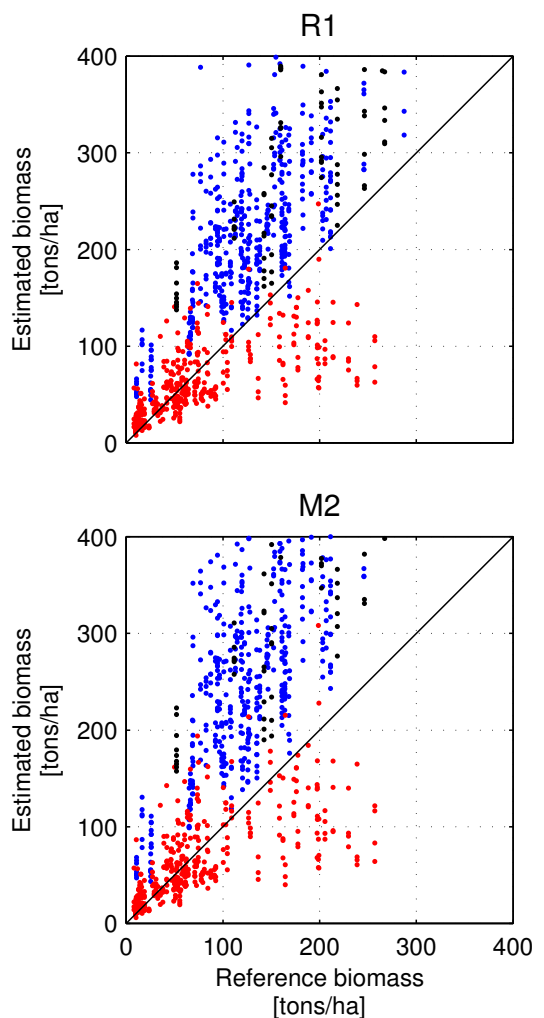
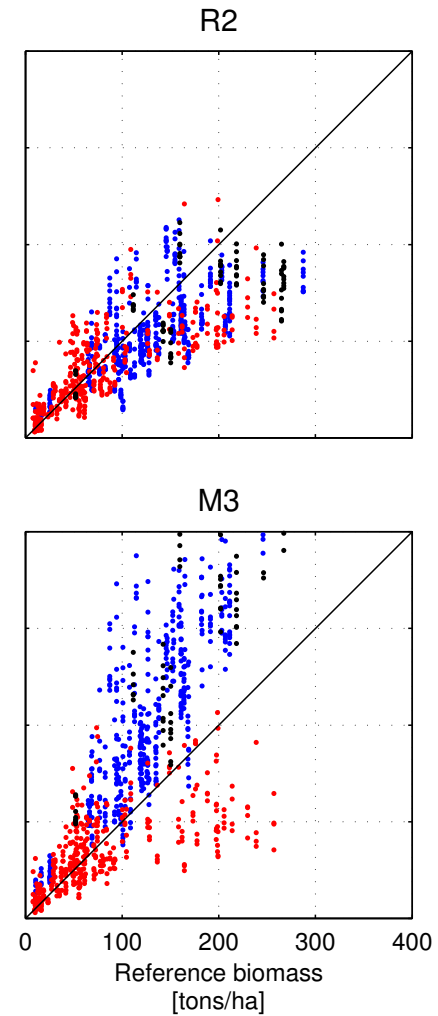
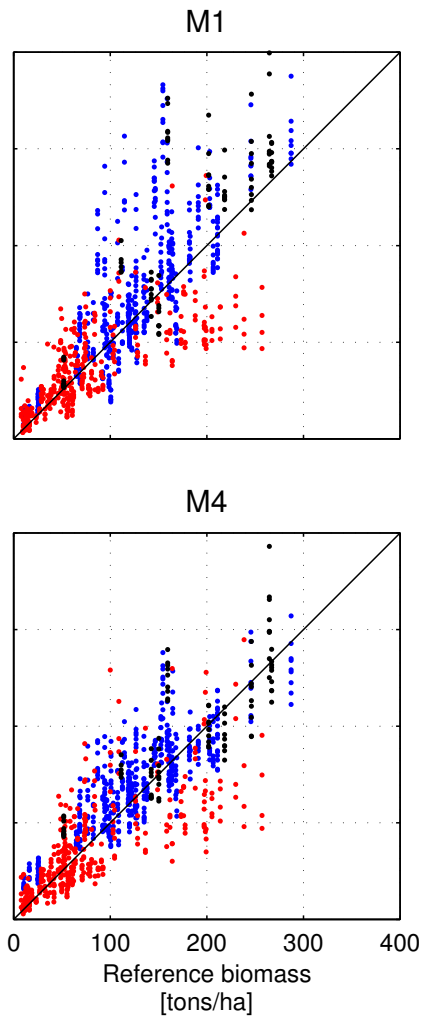

Parameters from Krycklan (all headings)

Retrieval results:

$\mathrm{Kr}, \mathrm{LID}$
$\mathrm{Re}, \mathrm{LID}$
$\mathrm{Re}, \mathrm{INS}$

Fig. 8. Comparison of the six evaluated models: training on Krycklan data. 

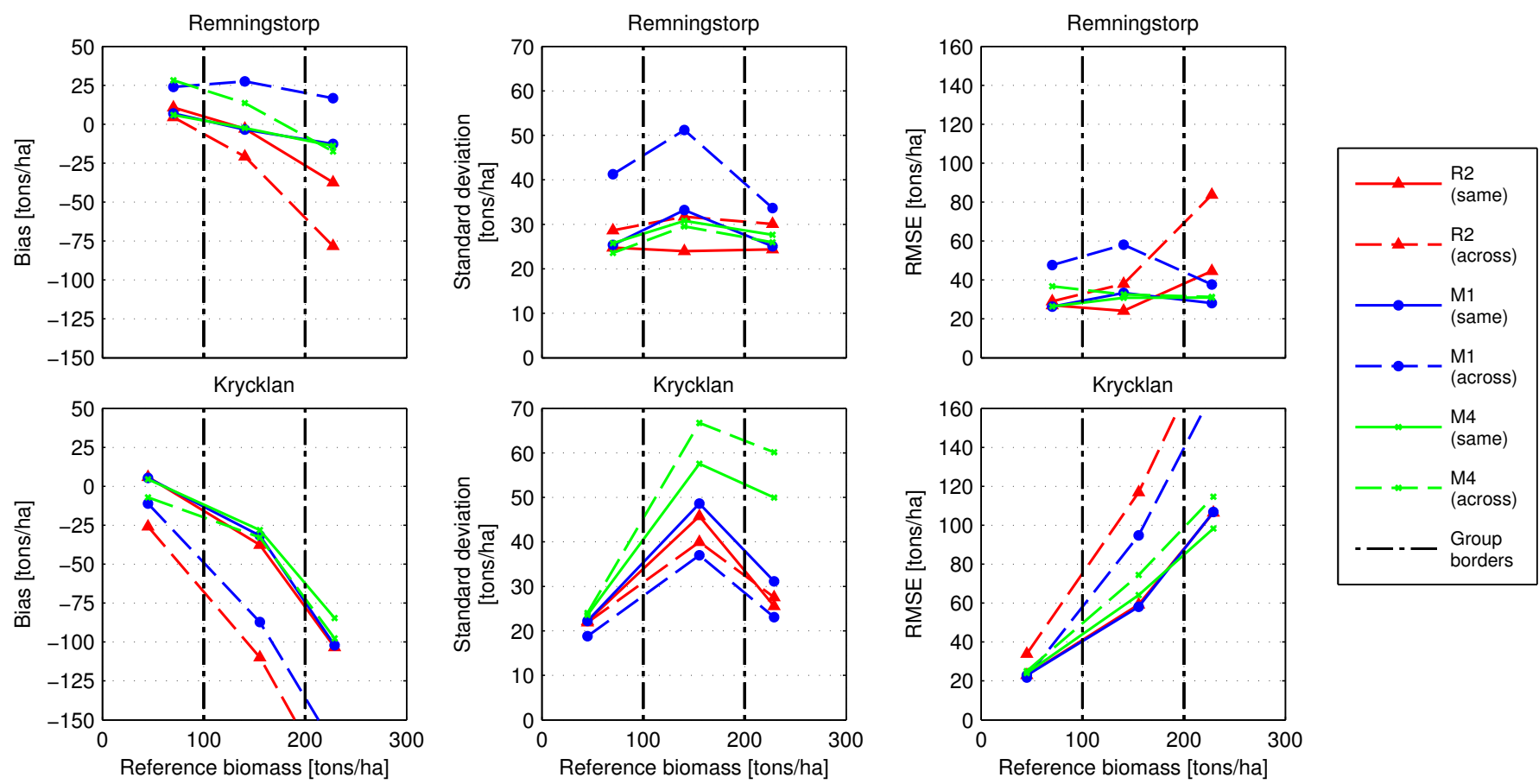

Fig. 9. Three different types of model errors are here plotted versus biomass: bias to the left, standard deviation of the estimation error in the middle, and RMSE to the right, as defined in (10)-(12). Only models (R2), (M1), and (M4) are compared. Model parameters as in Table IV were used. "Same" means that the model parameters estimated for the same site were used. "Across" means that the model parameters estimated for the other site were used. LID-stands were used and averaging was done in three intervals: 0-100 tons/ha, 100-200 tons/ha, and 200-300 tons/ha. The interval borders are plotted in blue dashed lines. The number of data points in each group is at least 50. Note: some lines may cover each other.

approximately $70 \mathrm{~m} \times 70 \mathrm{~m}$ to match the size of the smallest stand in the data sets used for training (0.5 ha). Biomass maps were then produced from all SAR images and averaged. In Fig. 10, only the regions covered by all acquisitions in the respective test sites are shown. The parameters used for map creation can be found in Table IV.

The SAR-based biomass maps show good qualitative agreement with the lidar-based maps. However, in some regions there are distinct differences between the maps. Three such examples are marked with black contours in Fig. 10.

In the large, irregular region " $\mathrm{A}$ " in the central-left part of Remningstorp, an overestimation with 100-150 tons/ha is observed. One $I N S$-stand (here called \#5, biomass: 167 tons/ha) is located within this region. A careful cross-check with reference in-situ and lidar data does not indicate any major issues related to the biomass map itself. However, according to Table 8.1 in [44], $50 \%$ of all trees in stand \#5 are pines, which contributes to $95 \%$ of the total biomass in this stand. The remaining $5 \%$ is concentrated in a layer of understorey vegetation. This fact has been observed during field visits, and it can also be seen in the lidar height data. The understorey layer makes a large contribution to the HV-backscatter through the increased number of vegetation scatterers. An investigation in the original SAR data shows, that HV is more affected by this vegetation layer than $\mathrm{HH}$.

In the oblong region "B", a disagreement of the order of 100-150 tons/ha between lidar and SAR biomass maps is observed in Fig. 10. One forest stand is located within region "B". This stand is shown in Figure 6.17 in [44] as
\#11 (biomass: 273 tons/ha, not used in this study due to its small size, $20 \mathrm{~m} \times 50 \mathrm{~m}$ ). An investigation of the lidar height data shows, that the high-biomass area containing stand \#11 is small and surrounded by sparser forest with lower trees. Therefore, filtering of the lidar map will lead to underestimation of biomass around stand \#11. Also, the DEM shows, that region "B" is located on a slope, which increases the HV-backscatter. This leads to an overestimation of biomass in the SAR-based biomass map. Summarising, the disagreement between lidar and SAR in region "B" is both due to an overestimation in the SAR map, and an underestimation in the lidar map.

Also in region "C", another disagreement is observed. The region consists of a group of tall trees situated on plane ground, with virtually no forest between them and the SAR. This increases the difference between HH- and VV-backscatter through the double-bounce effect, thus increasing the ratio. Moreover, smoothing of biomass map decreases the reference biomass level in a similar way as in region "B".

In Fig. 11 and Fig. 12, histograms and cumulative distributions for the relative error defined in (14) are shown. Here, the lidar-based biomass map was used as $\mathcal{B}_{\text {ref }}$ and the estimated SAR biomass maps were used as $\widehat{\mathcal{B}}$. The data have been divided in three biomass groups: 0-100 tons/ha, 100200 tons/ha, and 200 tons/ha and above. In the upper left corner of each subplot, the size of each group relative the total number of pixels in percent is shown (in parentheses, corresponding percentage of the training data in each group is shown). In black dashed lines, the corresponding distributions 
for the whole image are plotted.

In general, between 35 and $50 \%$ of all pixels are estimated with relative error smaller than $25 \%$. In Remningstorp, especially good estimation results are obtained for pixels with lidar biomass higher than 200 tons/ha (80-90\% pixels showed relative error smaller than $25 \%$ ). There is also a group of pixels with low lidar biomass, for which biomass is overestimated with more than $100 \%$. However, in terms of biomass error (measured in tons per hectare) this overestimation is not large.

In Krycklan, a general underestimation is observed for pixels with biomass larger than 100 tons/ha, especially when Remningstorp-based parameters are used. However, since only $12 \%$ of all pixels in the Krycklan map correspond to lidar biomass lower than 100 tons/ha, and the topography in Remningstorp is not strong, these results are less conclusive.

\section{SUMMARY AND CONCLUSIONS}

A new biomass retrieval model for boreal forest using polarimetric P-band SAR backscatter is presented in this paper. The model is based on two main SAR quantities: the HV backscatter and the HH/VV backscatter ratio, and it also includes a first order topographic correction, the ground slope angle $u$.

The paper is based on analysis of data from two airborne Pband SAR campaigns, BioSAR 2007 and 2008, conducted in the two Swedish test sites Remningstorp and Krycklan, separated by $720 \mathrm{~km}$. The examined stand-level biomass interval is 0-300 tons/ha and the surface slope goes up to $19^{\circ}$, measured on a $50 \mathrm{~m} \times 50 \mathrm{~m}$ posting DEM. Only forest stands with areas greater than 0.5 ha are used in this work. An average difference between the data from Remningstorp and Krycklan is observed in all polarisation channels, and more work is needed to fully understand and model it in terms of seasonal, topographic, and forest structure differences.

Compared to previously published models, the new model shows less bias induced by temporal change and topographic variability. Also, it gives reliable biomass retrieval results during across-site validation, that is when biomass estimation in one test site is evaluated using a model developed using data from the other test site.

Firstly, all relevant models were tested on data sets coming from Remningstorp, acquired at three occasions during the spring of 2007, each separated by roughly one month. This test showed, that the use of multiple polarisations significantly improves the performance. Also, the use of the HH/VV-ratio instead of HH- and VV-channels separately simplifies the model without sacrificing any performance.

The models were also tested for bias due to topographic variability using SAR data acquired from different directions in topographic terrain in Krycklan. The new model gave errors of $27-40$ tons/ha (corresponding to $29-43 \%$ of the the mean biomass in Krycklan, 95 tons/ha), whereas all the other models gave comparable or worse results. The results of this test were not conclusive, due to non-uniform biomass-slope distribution in the training data.

Thereafter, the across-site retrieval performance was evaluated. The test site used for training was thus distinctly different from the test site used for validation. With model parameters estimated on Krycklan data, biomass in Remningstorp could be estimated with root-mean-square errors of 40-59 tons/ha, or $22-32 \%$ of the mean biomass. The other models produced errors that were at least $50 \%$ higher. In the inverse scenario, the Krycklan site was not well represented in the training data set (too small topographic variability in Remningstorp), and errors of $35-51$ tons/ha were measured (37-54\% of the mean biomass in Krycklan). In terms of RMSE, the new model showed better results than the other models. The coefficient of determination $R^{2}$ was however low, and it was concluded that the training set was not sufficiently representative in terms of ground surface slopes.

Lastly, biomass maps estimated using the new model with two parameter sets (one for each test site) were compared to lidar-based biomass maps. The biomass maps were created by averaging biomass estimates from 6 SAR images in Remningstorp and 4 SAR images in Krycklan. A good qualitative agreement was observed between the lidar-based biomass maps and the SAR-based biomass maps. However, in some regions biomass was overestimated by SAR, which could be explained based on basic scattering properties of forest in connection to observations made in field and in the lidar data. Between 35 and $45 \%$ of all pixels in the maps were estimated with relative difference between the maps smaller than $25 \%$. In Remningstorp, especially good agreement was obtained for pixels with lidar-estimated biomass higher than 200 tons/ha (80-90\% pixels showed relative difference smaller than $25 \%$ ). In Krycklan, a general underestimation was observed for pixels with biomass larger than 100 tons/ha, especially when Remningstorp-based parameters were used. However, since only $12 \%$ of all pixels in the Krycklan map correspond to lidar biomass lower than 100 tons/ha, and the topography in Remningstorp is not strong, these results are not conclusive.

\section{ACKNOWLEDGMENT}

The authors would like to thank both the Swedish National Space Board (SNSB) and the European Space Agency (ESA) for funding this project, the German Aerospace Center (DLR) for the ESAR data, and Swedish University of Agricultural Sciences (SLU) for the field data.

\section{REFERENCES}

[1] IPCC, Climate Change 2007: The Physical Science Basis. Contribution of Working Group I to the Fourth Assessment Report of the Intergovernmental Panel on Climate Change, S. Solomon, M. M. Dahe Qin, M. Marquis, K. Averyt, M. M. B. Tignor, and H. L. Miller, Eds. Cambridge, United Kingdom and New York, NY, USA: Cambridge University Press, 2007.

[2] C. Parker, A. Mitchell, M. Trivedi, and N. Mardas, The Little REDD Book: A guide to governmental and non-governmental proposals for reducing emissions from deforestation and degradation. Global Canopy Programme, John Krebs Field Station, Oxford OX2 8QJ, UK, November 2008.

[3] E. Næsset, T. Gobakken, S. Solberg, T. G. Gregoire, R. Nelson, G. Ståhl, and D. Weydahl, "Model-assisted regional forest biomass estimation using lidar and InSAR as auxiliary data: A case study from a boreal forest area," Remote Sensing of Environment, vol. 115, no. 12, pp. 3599-3614, 2011. 


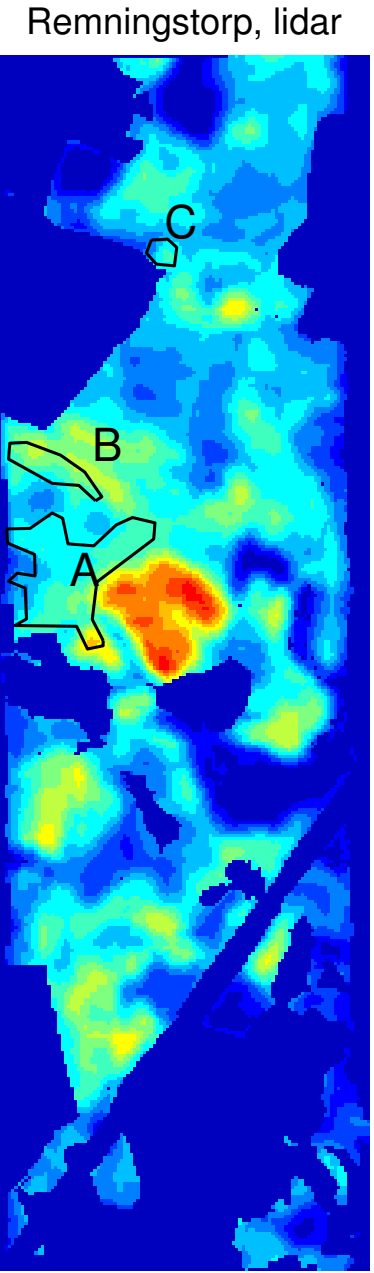

Krycklan, lidar

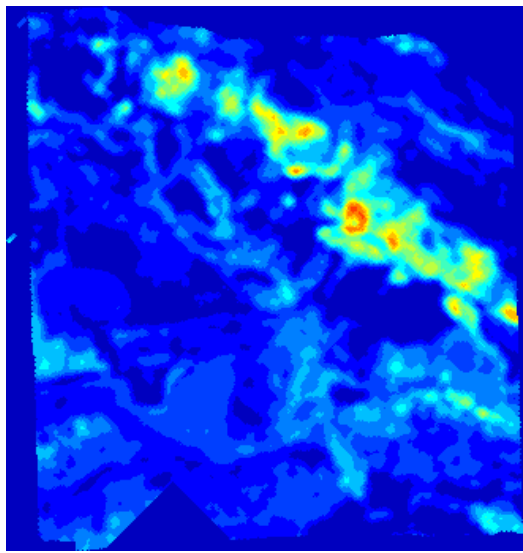

Remningstorp, (M4) for Re

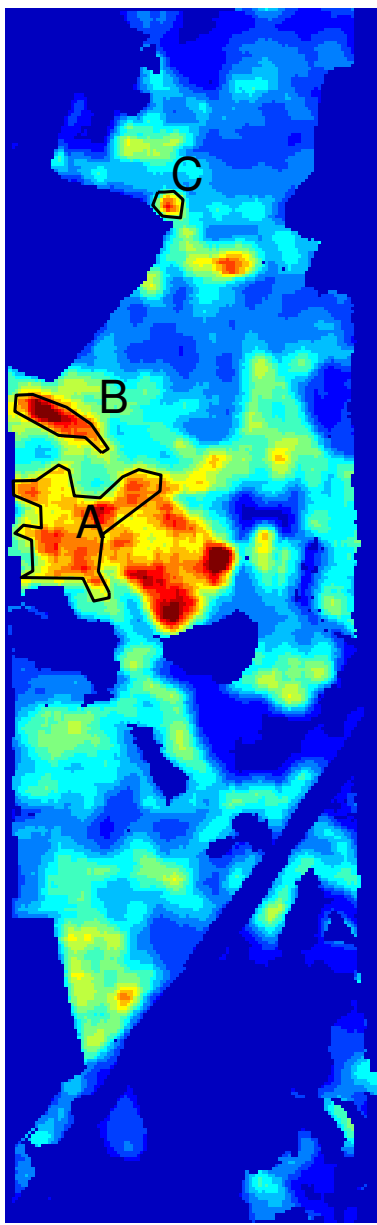

Krycklan, (M4) for Re

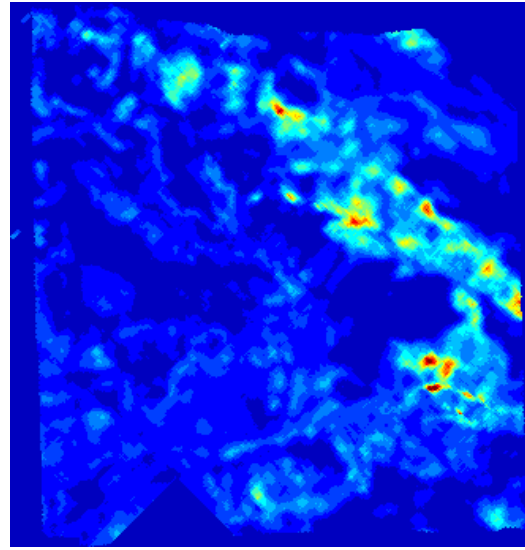

Biomass [tons/ha]
Remningstorp, (M4) for Kr

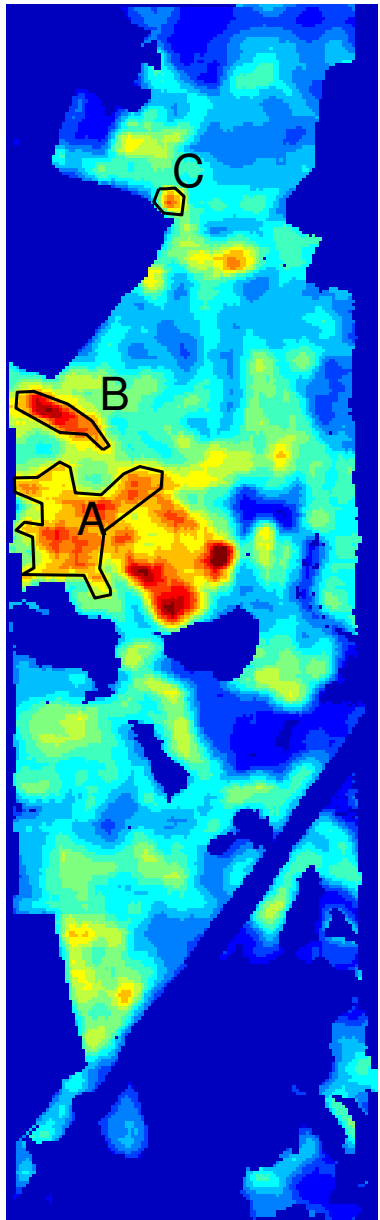

Krycklan, (M4) for Kr

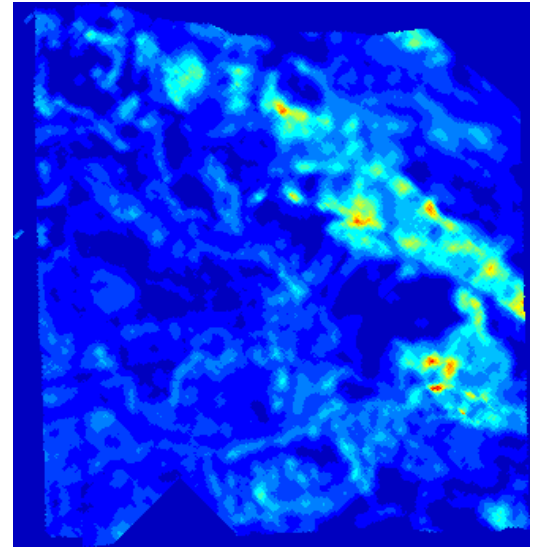

300

350

100

150

200

250

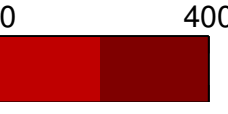

Fig. 10. Extracted biomass maps for Remningstorp and Krycklan. Biomass maps are quantised in intervals of 25 tons/ha. Model (M4) was used to create the maps. For Remningstorp, the north direction is upwards. All Krycklan-maps have been rotated by $45^{\circ}$ counter-clockwise for better viewing and the north east direction is upwards. In all images, the resolution is $70 \mathrm{~m} \times 70 \mathrm{~m}$ and the pixel size is $10 \mathrm{~m} \times 10 \mathrm{~m}$. The size of the imaged region is $3700 \mathrm{~m} \times 1130 \mathrm{~m}$ for Remningstorp and $3450 \mathrm{~m} \times 3270 \mathrm{~m}$ for Krycklan. The scales are the same in both $x$ - and $y$-direction. Three regions of interest discussed in Sec. IV-F are also marked. 

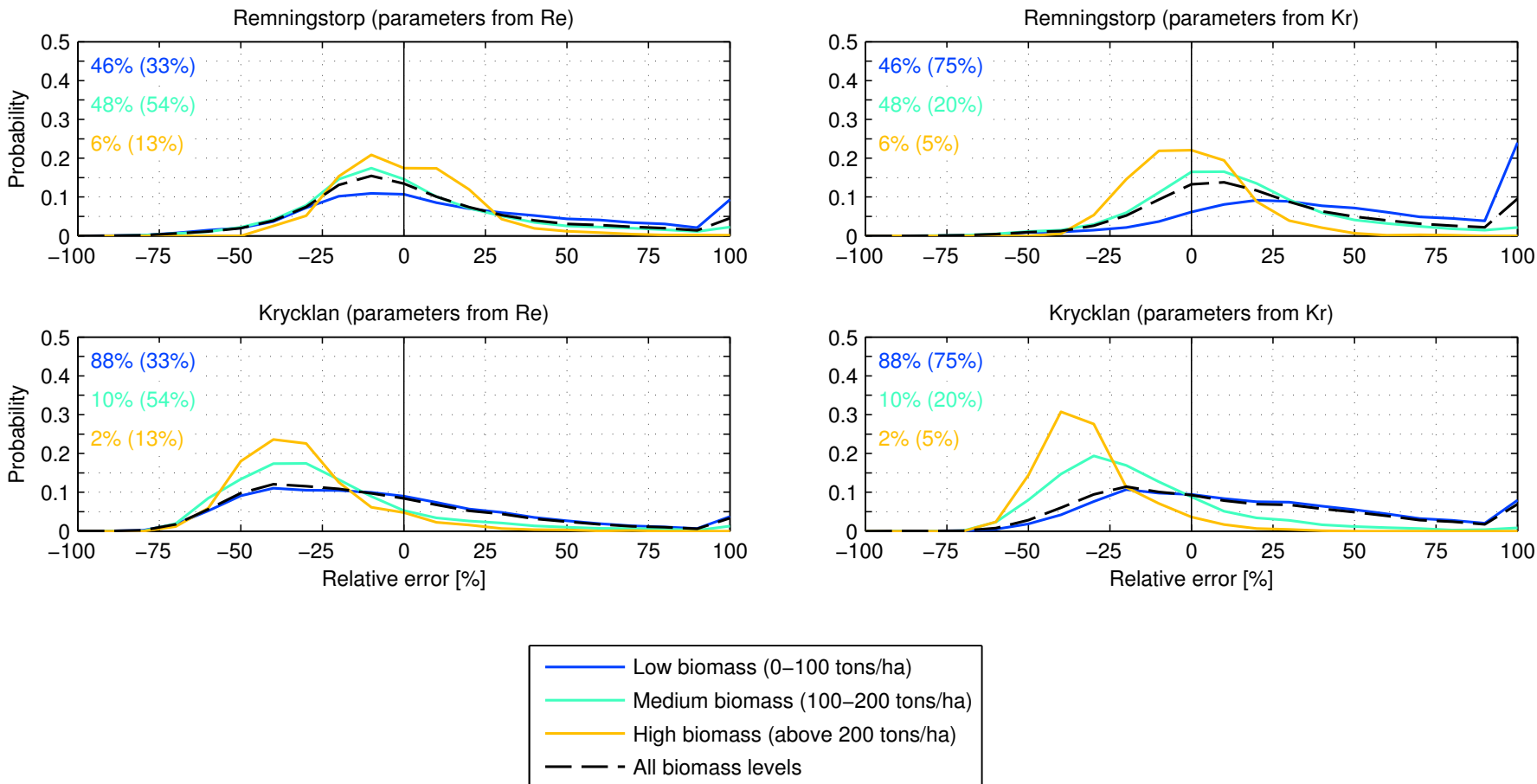

Fig. 11. Probability distributions for the relative difference between the lidar maps and the maps created using (M4) and SAR data are plotted here. Four curves are plotted, one for each biomass group (0-100 tons/ha, 100-200 tons/ha, and above 200 tons/ha), and one for all biomass levels. The distribution of the different groups among the image pixels are shown as percentage values in the upper left corner of each plot. In parentheses, the corresponding values for the training data are shown.
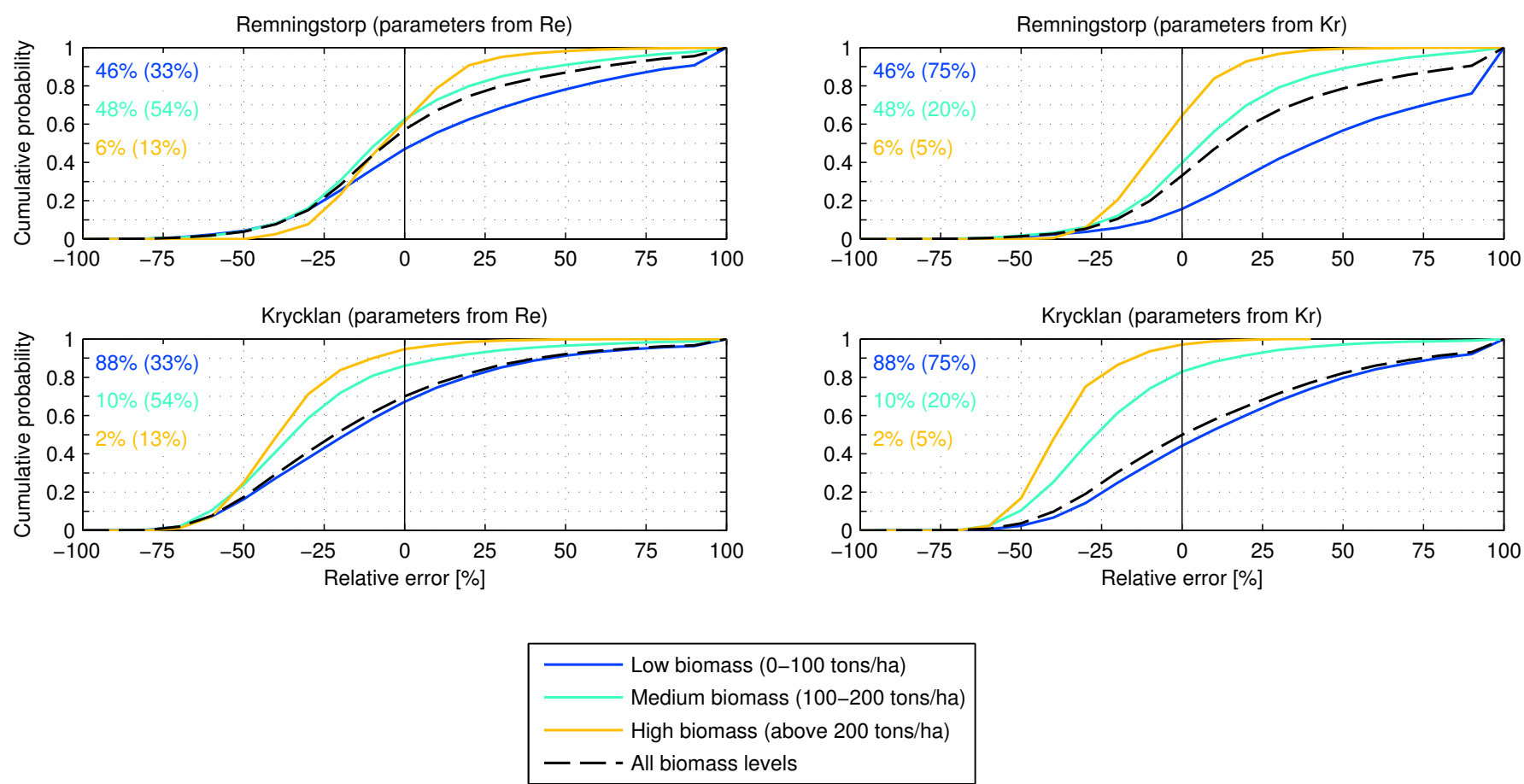

Fig. 12. Cumulative distributions for the relative difference between the lidar maps and the maps created using (M4) and SAR data are plotted here. Four curves are plotted, one for each biomass group (0-100 tons/ha, 100-200 tons/ha, and above 200 tons/ha), and one for all biomass levels. The distribution of the different groups among the image pixels are shown as percentage values in the upper left corner of each plot. In parentheses, the corresponding values for the training data are shown. 
[4] K. Folkesson, G. Smith-Jonforsen, and L. M. H. Ulander, "Model-based compensation of topographic effects for improved stem-volume retrieval from CARABAS-II VHF-band SAR images," IEEE Transactions on Geoscience and Remote Sensing, vol. 47, no. 4, pp. 1045-1055, April 2009.

[5] T. Le Toan, A. Beaudoin, J. Riom, and D. Guyon, "Relating forest biomass to SAR data," IEEE Transactions on Geoscience and Remote Sensing, vol. 30, no. 2, pp. 403-411, 1992.

[6] A. Beaudoin, T. L. Le Toan, S. Goze, E. Nezry, A. Lopes, E. Mougin, C. C. Hsu, H. C. Han, J. A. Kong, and R. T. Shin, "Retrieval of forest biomass from SAR data," International Journal of Remote Sensing, vol. 15 , no. 14 , pp. 2777-2796, 1994.

[7] H. Israelsson, J. Askne, and R. Sylvander, "Potential of SAR for forest bole volume estimation," International Journal of Remote Sensing, vol. 15, no. 14, pp. 2809-2826, 1994.

[8] Y. Rauste, T. Häma, J. P. ans K. Heiska, and M. Hallikainen, "Radar-based forest biomass estimation," International Journal of Remote Sensing, vol. 15, pp. 1797-2808, 1994.

[9] K. J. Ranson and G. Sun, "Mapping biomass of a northern forest using multifrequency SAR data," IEEE Transactions on Geoscience and Remote Sensing, vol. 32, no. 2, pp. 388-396, 1994.

[10] M. L. Imhoff, "Radar backscatter and biomass saturation: ramifications for global biomass inventory," IEEE Transactions on Geoscience and Remote Sensing, vol. 33, no. 2, pp. 511-518, 1995.

[11] E. J. Rignot, R. Zimmermann, and J. J. van Zyl, "Spaceborne applications of $\mathrm{P}$ band imaging radars for measuring forest biomass," IEEE Transactions on Geoscience and Remote Sensing, vol. 33, no. 5, pp. 1162-1169, 1995.

[12] D. H. Hoekman and M. J. Quiñones, "Land cover type and biomass classification using AirSAR data for evaluation of monitoring scenarios in the Colombian Amazon," IEEE Transactions on Geoscience and Remote Sensing, vol. 38, no. 2, pp. 685-696, 2000.

[13] J. R. Santos, C. C. Freitas, L. S. Araujo, L. V. Dutra, J. C. Mura F. F. Gama, L. S. Soler, and S. J. S. Sant'Anna, "Airborne P-band SAR applied to the aboveground biomass studies in the Brazilian tropical rainforest," Remote Sensing of Environment, vol. 87, no. 4, pp. 482-493, 2003.

[14] S. Saatchi, K. Halligan, D. Despain, and R. Crabtree, "Estimation of forest fuel load from radar remote sensing," IEEE Transactions on Geoscience and Remote Sensing, vol. 45, pp. 1726-1740, 2007.

[15] G. Sandberg, L. M. H. Ulander, J. E. S. Fransson, J. Holmgren, and T. Le Toan, "L- and P-band backscatter intensity for biomass retrieval in hemiboreal forest," Remote Sensing of Environment, vol. 115, no. 11, pp. 2874-2886, 2011

[16] S. Saatchi, M. Marlier, R. L. Chazdon, D. B. Clark, and A. E. Russell "Impact of spatial variability of tropical forest structure on radar estimation of aboveground biomass," Remote Sensing of Environment vol. 115 , no. 11 , pp. 2836-2849, 2011.

[17] M. Neumann, S. S. Saatchi, L. M. H. Ulander, and J. E. S. Fransson, "Assessing performance of L- and P-band polarimetric interferometric SAR data in estimating boreal forest above-ground biomass," IEEE Transactions on Geoscience and Remote Sensing, vol. 50, no. 3, pp. 714-726, March 2012.

[18] S. R. Cloude and K. P. Papathanassiou, "Polarimetric SAR interferometry," IEEE Transactions on Geoscience and Remote Sensing, vol. 36, no. 5, pp. 1551-1565, 1998.

[19] K. P. Papathanassiou and S. R. Cloude, "Single-baseline polarimetric SAR interferometry," IEEE Transactions on Geoscience and Remote Sensing, vol. 39, pp. 2352-2363, 2001.

[20] S. R. Cloude and K. P. Papathanassiou, "Three-stage inversion process for polarimetric SAR interferometry," IEE Proceedings on Radar, Sonar \& Navigation, vol. 150, no. 3, pp. 125-134, 2003.

[21] I. H. Woodhouse, "Predicting backscatter-biomass and height-biomass trends using a macroecology model," IEEE Transactions on Geoscience and Remote Sensing, vol. 44, no. 4, pp. 871-877, April 2006.

[22] M. Neumann, L. Ferro-Famil, and A. Reigber, "Multibaseline polarimetric SAR interferometry coherence optimization," IEEE Geoscience and Remote Sensing Letters, vol. 5, no. 1, pp. 93-97, January 2008.

[23] —, "Estimation of forest structure, ground, and canopy layer characteristics from multibaseline polarimetric interferometric SAR data," IEEE Transactions on Geoscience and Remote Sensing, vol. 48, no. 3, pp. 1086-1104, March 2010.

[24] A. Reigber and A. Moreira, "First demonstration of airborne SAR tomography using multibaseline L-band data," IEEE Transactions on Geoscience and Remote Sensing, vol. 38, no. 5, pp. 2142-2152, September 2000.
[25] S. R. Cloude, "Polarization coherence tomography," Radio Science, vol. 41, 2006.

[26] S. Tebaldini, "Single and multipolarimetric SAR tomography of forested areas: A parametric approach," IEEE Transactions on Geoscience and Remote Sensing, vol. 48, no. 5, pp. 2375-2387, May 2010.

[27] B. Hallberg, G. Smith-Jonforsen, L. M. H. Ulander, and G. Sandberg, "A physical-optics model for double-bounce scattering from tree stems standing on an undulating ground surface," IEEE Transactions on Geoscience and Remote Sensing, vol. 46, no. 9, pp. 2607-2621, 2008.

[28] G. Smith-Jonforsen, L. M. H. Ulander, and X. Luo, "Low VHFband backscatter from coniferous forests on sloping terrain," IEEE Transactions on Geoscience and Remote Sensing, vol. 43, no. 10, pp. 2246-2260, 2005

[29] J. J. van Zyl, "The effect of topography on radar scattering from vegetated areas," IEEE Transactions on Geoscience and Remote Sensing, vol. 31, no. 1, pp. 153-160, 1993.

[30] Y.-C. Lin and K. Sarabandi, "Electromagnetic scattering model for a tree trunk above a tilted ground plane," IEEE Transactions on Geoscience and Remote Sensing, vol. 33, no. 4, pp. 1063-1070, July 1995.

[31] Y. Dong and J. A. Richards, "Studies of the cylinder-ground double bounce scattering mechanism in forest backscatter models," IEEE Transactions on Geoscience and Remote Sensing, vol. 33, no. 1, pp. 229-231, January 1995.

[32] J. Lopez-Sanchez, H. Esteban-Gonzalez, M. Baquero-Escudero, and J. Fortuny-Guasch, "An electromagnetic scattering model for multiple tree trunks above a tilted rough ground plane," IEEE Transactions on Geoscience and Remote Sensing, vol. 37, no. 2, pp. 659-667, March 1999.

[33] G. Smith and L. M. H. Ulander, "A model relating VHF-band backscatter to stem volume of coniferous boreal forest," IEEE Transactions on Geoscience and Remote Sensing, vol. 38, no. 2, pp. 728-740, March 2000.

[34] M. L. Williams, PolSARproSim: A Coherent, Polarimetric SAR Simulation of Forests for PolSARPro; Design Document and Algorithm Specification (u1.0), December 2006.

[35] "Candidate Earth Explorer Core Mission: BIOMASS, Report for Assessment," European Space Agency (SP-1212/2), Tech. Rep., 2008.

[36] M. Arcioni, P. Bensi, J.-L. Bézy, B. Carnicero, M. Davidson, M. Drinkwater, F. Fois, A. Gabriele, R. Haagmans, F. Hélière, P. Ingmann, V. Kangas, M. Kern, S. Kraft, J. Langen, A. Lecuyot, C.-C. Lin, R. Meynart, K. Scipal, and P. Silvestrin, "Biomass, CoReH2O, PREMIER: ESA's candidate 7th Earth Explorer missions," in IEEE International Geoscience and Remote Sensing Symposium (IGARSS), Honolulu, HI, USA, July 2010, pp. 673-676.

[37] K. Scipal, M. Arcioni, J. Chave, J. Dall, F. Fois, T. Le Toan, C. Lin, K. Papathanassiou, S. Quegan, F. Rocca, S. Saatchi, H. Shugart, L. Ulander, and M. Williams, "The BIOMASS mission - an ESA Earth Explorer candidate to measure the biomass of the Earth's forests," in IEEE International Geoscience and Remote Sensing Symposium (IGARSS), Honolulu, HI, USA, July 2010, pp. 52-55.

[38] T. Le Toan, S. Quegan, M. W. J. Davidson, H. Balzter, P. Paillou, K. Papathanassiou, S. Plummer, F. Rocca, S. Saatchi, H. Shugart, and L. Ulander, "The BIOMASS mission: Mapping global forest biomass to better understand the terrestrial carbon cycle," Remote Sensing of Environment, vol. 115, no. 11, pp. 2850-2860, 2011.

[39] S. Quegan, T. Le Toan, J. Chave, J. Dall, K. P. Papathanassiou, F. Rocca, L. Ulander, M. Williams, S. S. Saatchi, and H. Shugart, "BIOMASS, Report for Mission Selection," European Space Agency (SP-1324/1), Tech. Rep., 2012.

[40] M. J. Soja, G. Sandberg, and L. M. H. Ulander, "Topographic correction for biomass retrieval from P-band SAR data in boreal forests," in IEEE International Geoscience and Remote Sensing Symposium (IGARSS), Honolulu, HI, USA, 2010, pp. 4776-4779.

[41] G. Sandberg, M. J. Soja, and L. M. H. Ulander, "Impact and modeling of topographic effects on P-band SAR backscatter from boreal forests," in IEEE International Geoscience and Remote Sensing Symposium (IGARSS), Vancouver, BC, Canada, 2011, pp. 3522-3525.

[42] M. Neumann, S. S. Saatchi, L. M. H. Ulander, and J. E. S. Fransson, "Parametric and non-parametric forest biomass estimation from PolInSAR data," in IEEE International Geoscience and Remote Sensing Symposium (IGARSS), Vancouver, BC, Canada, July 2011, pp. $420-423$.

[43] L. M. H. Ulander, G. Sandberg, and M. J. Soja, "Biomass retrieval algorithm based on P-band BioSAR experiments of boreal forest," in IEEE International Geoscience and Remote Sensing Symposium (IGARSS), Vancouver, BC, Canada, July 2011, pp. 4245-4248. 
[44] I. Hajnsek, R. Scheiber, L. Ulander, A. Gustavsson, G. Sandberg, S. Tebaldini, A. M. Guarnieri, F. Rocca, F. Bombardini, and M. Pardini, "BioSAR 2007 technical assistance for the development of airborne SAR and geophysical measurements during the BioSAR 2007 experiment: Final report without synthesis," ESA contract no. 20755/07/NL/CB, Tech. Rep., 2008.

[45] I. Hajnsek, R. Scheiber, M. Keller, R. Horn, S. Lee, L. M. H. Ulander, A. Gustavsson, G. Sandberg, T. Le Toan, S. Tebaldini, A. M. Guarnieri, and F. Rocca, "BioSAR 2008 technical assistance for the development of airborne SAR and geophysical measurements during the BioSAR 2008 experiment: Final report - BioSAR campaign,” ESA contract no. 22052/08/NL/CT, Tech. Rep., 2009.

[46] L. M. H. Ulander, A. Gustavsson, P. Dubois-Fernandez, X. Depuis, J. E. S. Fransson, J. Holmgren, J. Wallerman, L. E. B. Eriksson, G. Sandberg, and M. J. Soja, "BioSAR 2010 - a SAR campaign in support to the BIOMASS mission," in IEEE International Geoscience and Remote Sensing Symposium (IGARSS), Vancouver, BC, Canada, July 2011, pp. $1528-1531$.

[47] L. M. H. Ulander, A. Gustavsson, B. Flood, D. Murdin, P. DuboisFernandez, X. Depuis, G. Sandberg, M. J. Soja, L. E. B. Eriksson, J. E. S. Fransson, J. Holmgren, and J. Wallerman, "BioSAR 2010 Technical Assistance for the Development of Airborne SAR and Geophysical Measurements during the BioSAR 2010 Experiment: Final Report," ESA contract no. 4000102285/10/NL/JA/ef, Tech. Rep., 2011.

[48] J. E. S. Fransson, F. Walter, and L. M. H. Ulander, "Estimation of forest parameters using CARABAS-II VHF SAR data," IEEE Transactions on Geoscience and Remote Sensing, vol. 38, no. 2, pp. 720-727, March 2000.

[49] L. G. Marklund, "Biomassafunktioner för tall, gran och björk i Sverige," Institutionen för skogstaxering, Sveriges lantbruksuniversitet, Umeå, Sweden, Rapport 45, 1988, (in Swedish).

[50] H. Petersson, "Biomassafunktioner for trädfraktioner av tall, gran och björk i sverige," SLU, Institutionen för skoglig resurshållning och geomatik, Arbetsrapport 59, Umeå, Tech. Rep., 1999, (in Swedish).

[51] J. E. S. Fransson, M. Magnusson, G. Sandberg, L. M. H. Ulander, and A. Gustavsson, "Forest database for single trees in Remningstorp, Västergötland, Sweden, version 2.0," 2008, Swedish University of Agricultural Sciences, Umeå (unpublished).

[52] J.-S. Lee and E. Pottier, Polarimetric Radar Imaging: From Basics to Applications. CRC Press, 2009.

[53] L. M. H. Ulander, "Radiometric slope correction of synthetic aperture radar images," IEEE Transactions on Geoscience and Remote Sensing, vol. 34 , no. 5, pp. 1115-1122, 1996.

[54] T. Le Toan, L. Ulander, G. Sandberg, B. Petrucci, L. Villard, P. Borderies, P. Dubois-Fernandez, S. Angelliaume, M. Quiñones, D. Hoekman, K. Papathanassiou, F. Kugler, S.-K. Lee, F. Garestier, A. Couhert, and J. Valteau, "P-band SAR wave interaction and information retrieval: Analysis and inversion of P-band SAR data for forest biomass and height mapping," Final Report, ESA Contract No. 20290/06/NL/LvH, Tech. Rep., 2011.

[55] N. R. Draper and H. Smith, Applied Regression Analysis, 3rd ed. John Wiley \& Sons Inc., 1998.

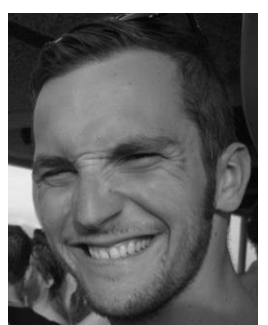

Maciej Jerzy Soja was born in 1985 in Warsaw, Poland. He received the B.Sc. and M.Sc. degree in engineering physics from Chalmers University of Technology, Gothenburg, Sweden, in 2008 and 2009, respectively. Since December 2009, he is pursuing his Ph.D. degree in remote sensing in the Radar Remote Sensing Group at the Department of Earth and Space Sciences at Chalmers University of Technology. His main research topic is synthetic aperture radar in forestry.

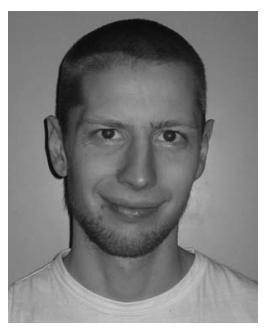

Gustaf Sandberg received the M.Sc. degree in engineering physics from the Chalmers University of Technology, Gothenburg, Sweden, in 2006, where he is currently working toward the Ph.D. degree in the Department of Earth and Space Sciences. His main research interests lie in synthetic aperture radar analysis, with emphasis on ionospheric effects as well as L- and P-band measurements of forests.

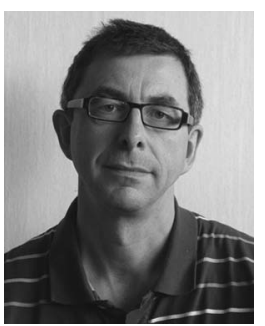

Lars M. H. Ulander (S'86-M'90-SM'04) received the M.Sc. degree in engineering physics in 1985 and the Ph.D. degree in electrical and computer engineering in 1991, both from Chalmers University of Technology. Since 1995 he has been with the Swedish Defence Research Agency (FOI) in Linköping where he is Director of Research in radar signal processing. He is also Adjunct Professor in radar remote sensing at Chalmers University of Technology. His research areas are synthetic aperture radar (SAR), electromagnetic scattering models and remote sensing applications. He is the author or co-author of over 250 professional publications, of which more than 50 are in peer-reviewed scientific journals. He is the holder of five patents and is also a member of the Remote Sensing Committee at the Swedish National Space Board. 